\title{
Uterine fibroids: current perspectives
}

This article was published in the following Dove Press journal:

International Journal of Women's Health

29 January 2014

Number of times this article has been viewed

\author{
Aamir T Khan' \\ Manjeet Shehmar' \\ Janesh K Gupta ${ }^{2}$ \\ 'Birmingham Women's Hospital, \\ Edgbaston, Birmingham, UK; \\ ${ }^{2}$ Academic Department of Obstetrics \\ and Gynaecology, University of \\ Birmingham, Birmingham, UK
}

\begin{abstract}
Uterine fibroids are a major cause of morbidity in women of a reproductive age (and sometimes even after menopause). There are several factors that are attributed to underlie the development and incidence of these common tumors, but this further corroborates their relatively unknown etiology. The most likely presentation of fibroids is by their effect on the woman's menstrual cycle or pelvic pressure symptoms. Leiomyosarcoma is a very rare entity that should be suspected in postmenopausal women with fibroid growth (and no concurrent hormone replacement therapy). The gold standard diagnostic modality for uterine fibroids appears to be gray-scale ultrasonography, with magnetic resonance imaging being a close second option in complex clinical circumstances. The management of uterine fibroids can be approached medically, surgically, and even by minimal access techniques. The recent introduction of selective progesterone receptor modulators (SPRMs) and aromatase inhibitors has added more armamentarium to the medical options of treatment. Uterine artery embolization (UAE) has now been well-recognized as a uterine-sparing (fertility-preserving) method of treating fibroids. More recently, the introduction of ultrasound waves (MRgFUS) or radiofrequency (VizAblate ${ }^{\mathrm{TM}}$ and Acessa $^{\mathrm{TM}}$ ) for uterine fibroid ablation has added to the options of minimal access treatment. More definite surgery in the form of myomectomy or hysterectomy can be performed via the minimal access or open route methods. Our article seeks to review the already established information on uterine fibroids with added emphasis on contemporary knowledge.
\end{abstract}

Keywords: leiomyoma, menorrhagia, ultrasonography, selective progesterone receptor modulators, uterine artery embolization, myomectomy

\section{Introduction}

Uterine fibroids (also known as leiomyomas or myomas) are the commonest benign uterine tumors, with an estimated incidence of $20 \%-40 \%$ in women during their reproductive years. ${ }^{1,2}$ They are monoclonal tumors of the uterine smooth muscle cells and consist of large amounts of extracellular matrix that contain collagen, fibronectin, and proteoglycan. ${ }^{3,4}$ Even though their pathogenesis is not clearly known, there is considerable evidence that estrogens and progestogens proliferate tumor growth, ${ }^{5,6}$ as the fibroids rarely appear before menarche ${ }^{7}$ and regress after menopause. ${ }^{8}$ They are classified by their location relative to the layers of the uterus (as subserous, intramural, or submucous) and can be single or multiple.

\section{Epidemiology and etiology Race and age}

A study carried out in the USA with randomly selected women between the ages of 35 and 49 years (who were screened by self-report, medical record, and sonography) 
showed that the incidence of uterine fibroids by age 35 was $60 \%$ among African-American women, increasing to $>80 \%$ by age 50 , whereas Caucasian women showed an incidence of $40 \%$ by age 35 , and almost $70 \%$ by age $50 .{ }^{9}$

The cumulative incidence (based both on ultrasonographic detection of fibroids in women with an intact uterus and evidence of prior fibroids among women who have had hysterectomies) increases with age, but the rate of increase slows at older ages. This suggests that the older premenopausal uterus is less susceptible to fibroid development. ${ }^{10}$

\section{Early menarche}

Most of the older studies (reviewed by Schwartz) ${ }^{11}$ had reported an increased risk of fibroids with earlier age of menarche and the newer data confirm these findings. Early age of menarche is also a risk factor for other hormonally mediated conditions such as endometrial and breast cancers. ${ }^{12,13}$ The biological mechanisms are not understood, and they may or may not be the same for the different hormonally mediated conditions.

\section{Parity and pregnancy}

Parity has been inversely associated with a risk of fibroid development in the earlier studies, ${ }^{14}$ and the newer studies confirm these findings. ${ }^{15,16}$ Although a direct protective effect of pregnancy has been demonstrated, little is known of the mechanism. There have been some suggestions that during postpartum uterine remodeling, there could be selective apoptosis of small lesions. ${ }^{14}$ Ischemia during parturition has also been proposed as a mechanism. ${ }^{17}$ Thus, it may be implied that fibroid tissue could be highly susceptible to ischemia during both parturition and remodeling. ${ }^{10}$

\section{Caffeine intake}

There has been recent evidence suggesting a relationship between alcohol and caffeine intake with a risk of developing fibroids, especially with evidence gathered from the Black Women's Health Study. ${ }^{18}$ Current drinkers had significantly higher risks than women who had never consumed alcohol, and there appears to be a dose response for both duration of alcohol consumption and number of drinks per day. With regards to caffeine, among women $<35$ years of age, the highest categories of caffeinated coffee ( $\geq 3$ cups/day) and caffeine intake ( $\geq 500 \mathrm{mg} /$ day) were both associated with increased fibroid risk. ${ }^{10}$

\section{Other possible factors}

There is contemporary interest in the influence of dynamics encompassing the likes of uterine infection, hormonal, metabolic, dietary, stress, and environmental factors. The underlying biological mechanism of infection-related oncogenesis proposed is that injury caused by infection or inflammation proceeds through several possible pathways, leading to increased extracellular matrix, cell proliferation, and decreased apoptosis, apropos of abnormal tissue repair. ${ }^{19-22}$ The upregulation of extracellular matrix proteins that is consistently seen in gene profiling studies of fibroids compared with normal myometrium ${ }^{23}$ is consistent with such a mechanism. As luteinizing hormone (LH) shares a receptor with human chorionic gonadotropin, the hormone that stimulates uterine growth during early pregnancy, it is hypothesized that peri-menopausal increases in LH would stimulate fibroid growth. ${ }^{24}$ Metabolic factors like diabetes, polycystic ovaries, and hypertension have been examined. Dietary factors have looked at the intake of soy which tends to have anti-estrogenic effects when endogenous estrogens are high (ie, premenopausal women), thus hypothesizing that soy intake might reduce fibroid risk. ${ }^{10} \mathrm{~A}$ possible mechanism of the impact of stress involves the effects of stress on adrenal activity that could raise progesterone levels, ${ }^{25}$ and thus increase fibroid development. All these areas of interest are currently hypothetical and need further study to clarify their exact role in the etiology of fibroids.

\section{Presentation}

Uterine fibroids are the cause for some of the most common gynecological problems among women presenting to gynecology emergency and outpatient departments in the UK. They are often asymptomatic but they can cause a multitude of symptoms (Table 1) such as abnormal uterine bleeding, a feeling of pelvic pressure, urinary incontinence or retention, or pain. They may also be associated with reproductive problems such as infertility and miscarriage. ${ }^{26}$

The presenting symptoms play an important role in deciding the appropriate form of treatment for the affected woman. Management strategies are usually individualized based on the severity of the symptoms, the size and location of the fibroid, the patient's age and their chronological proximity to menopause, and the patient's desire for future fertility. ${ }^{27}$ The majority of women with uterine fibroids are asymptomatic, and consequently get less clinical attention; fibroid tumors often remain undiagnosed. ${ }^{28,29}$ The most common presenting factor that symptomatic women typically complain about is abnormal uterine bleeding, specifically in terms of heavy and prolonged bleeding. ${ }^{1}$ In a study by Wegienka et al, women with myomas were more likely to report a 'gushing' type of bleeding and higher pad/tampon use than women 
Table I The clinical presentation of uterine leiomyomas

\begin{tabular}{l}
\hline i. Asymptomatic \\
ii. Abnormal uterine bleeding \\
a. Menorrhagia \\
b. Anemia \\
iii. Pelvic pressure \\
a. Urinary frequency \\
b. Urinary incontinence \\
c. Difficulty with urination \\
d. Hydronephrosis \\
e. Constipation \\
f. Tenesmus \\
iv. Pelvic mass \\
v. Pelvic pain \\
vi. Infertility \\
vii. Obstetric complications \\
viii. Pregnancy related \\
a. Myoma growth \\
b. Red degeneration and pain \\
c. Spontaneous miscarriage \\
ix. Malignancy \\
x. Rare associations \\
a. Ascites \\
b. Polycythemia \\
c. Familial syndromes, renal cell carcinoma \\
xi. Benign metastasizing \\
\hline
\end{tabular}

Note: Adapted from Sabry and Al-Hendy. Innovative oral treatments of uterine leiomyoma. Obstet Gynecol Int. 20I2;20I2:943635. ${ }^{27}$

without myomas. ${ }^{30}$ In addition, women with uterine fibroids may suffer more often from dyspareunia and non-cyclic pelvic pain. ${ }^{31}$ Although bleeding and pelvic pain symptoms are frequently reported in literature as the main symptoms related to uterine fibroids, the number of systematic studies on fibroid symptoms is limited. ${ }^{32}$

\section{Diagnosis}

Precise uterine fibroid mapping (localization, measurement, and characterization) is essential for research into clarifying the natural history of these tumors and for evaluating therapeutic responses to investigational agents. ${ }^{33}$ The optimal selection of patients for medical therapy, noninvasive procedures, or surgery depends on an accurate assessment of the size, number, and position of myomas. Imaging techniques available for confirming the diagnosis of myomas include sonography, saline-infusion sonography, and MRI. ${ }^{34}$

\section{Ultrasonography}

Ultrasonography using the transabdominal and transvaginal routes has been employed most frequently, due to its accessibility and relatively low cost. ${ }^{35}$ While a cost-effective instrument, ultrasound has been criticized for its significant operator-dependence, resulting in inferior reproducibility when compared to MRI. ${ }^{36-39}$ Ideally, both transabdominal and transvaginal scans should be performed. Transvaginal scans are more sensitive for the diagnosis of small fibroids. However, when the uterus is bulky or retroverted, the uterine fundus may lie outside of the field of view. Transabdominal views are often of limited value if the patient is obese. Ultrasonography in skilled hands can detect fibroids as small as $5 \mathrm{~mm}$ on transvaginal ultrasounds. Typically, fibroids appear as well-defined, solid masses with a whorled appearance (Figure 1). These are usually of similar echogenicity to the myometrium, but sometimes may be hypoechoic. They cause the uterus to appear bulky or may cause an alteration of the normal uterine contour. Even non-calcified fibroids often show a degree of posterior acoustic shadowing, though this is of course more marked in calcified fibroids. Degenerate fibroids may have a complex appearance, with areas of cystic change. ${ }^{40}$ Doppler ultrasound typically shows circumferential vascularity. However, fibroids which are necrotic or have undergone torsion will show absence of flow. ${ }^{41}$ Submucous fibroids are usually clearly visible separate from the endometrium under transvaginal ultrasound, but can be difficult to differentiate from polyps. ${ }^{40}$ Sonography may be inadequate for determining the precise number and position of myomas, although transvaginal sonography is reasonably reliable for uteri $<375 \mathrm{~mL}$ in total volume or containing four myomas or fewer. ${ }^{42}$ Large fibroids can occasionally cause obstruction of the ureters, with secondary hydronephrosis. Therefore, ultrasound examination should include the urinary tract whenever a large pelvic mass is identified. The diagnosis of fibroids on ultrasound is usually reasonably straightforward though focal adenomyosis can mimic a fibroid and a pedunculated uterine fibroid can sometimes be mistaken for an adnexal mass. ${ }^{43}$ When there is doubt about the origin of a pelvic mass at ultrasound, further evaluation with MRI should be performed. ${ }^{40}$

\section{Saline infusion sonohysterography}

Saline infusion sonohysterography-based imaging is usually used as a supplementary or adjunct imaging modality for characterization of focal uterine masses diagnosed on B-mode ultrasound images. During transvaginal ultrasound, a uterine mass may appear as an area of increased echogenicity bulging into the endometrial cavity with echogenicity similar to that of the myometrium. In addition, it is difficult to distinguish a leiomyoma from a blood clot or a polyp, and leiomyomas also may obscure the endometrium on imaging or cause an overestimation of endometrial thickness. Transvaginal sonography may be used initially in the detection of endometrial polyps, which may appear as hyperechoic masses surrounded 


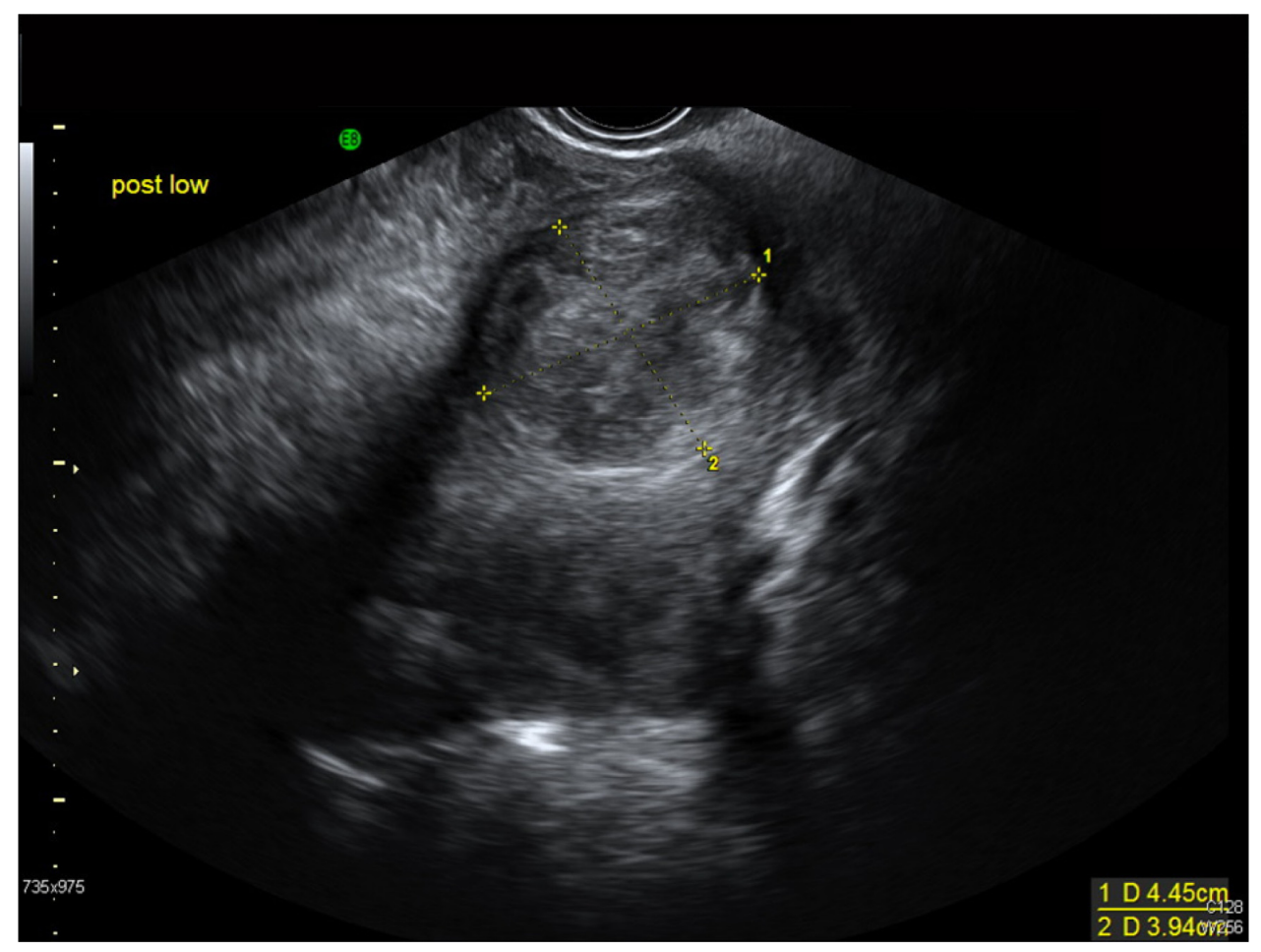

Figure I A 37-year-old Afro-Caribbean woman with a history of menorrhagia. Transvaginal ultrasound image showed a bulky fibroid uterus with multiple intramural fibroids. The largest fibroid (pictured above) is at the fundus on the posterior wall measuring $4.5 \times 4 \mathrm{~cm}$.

by a hypoechoic endometrium. ${ }^{44}$ However, it may be difficult to detect some polyps because they may appear as a diffusely thickened endometrium. ${ }^{45}$ Nevertheless, polyps may be better visualized during saline infusion sonohysterography, in which the saline pushes apart the uterine cavity, and the polyps appear as smoothly margined focal lesions that protrude into the endometrial cavity (Figure 2). Saline infusion sonohysterography is also effective in distinguishing diffuse endometrial changes and focal intracavitary protuberances. ${ }^{44}$ However, it is limited in its ability to differentiate between endometrial hyperplasia (premalignant polyps) and endometrial carcinoma. ${ }^{46}$

The quality of the image obtained is dependent on the amount of deformation induced by the saline injection into the uterine cavity. If the amount of saline injected is too low, the deformation induced is too small to provide images with a reasonable signal-to-noise ratio. This situation has led to generation of suboptimal strain images in some instances because of the minimal deformation of the tissue. The amount of deformation applied via saline injection is dependent on the ability of the patient to tolerate the discomfort induced due to saline injection into the uterus; in other cases, insufficient deformation is due to the presence of saline from a previous infusion and the inability to withdraw sufficient fluid before starting a new infusion. Patient comfort is of paramount importance during the data acquisition because saline injection can be quite painful and distressing to the patient. Care should be taken to induce a sufficient deformation of the uterine wall that is tolerated by the patient to obtain high-quality strain images. The use of saline infusion sonohysterography-based strain imaging as a standalone imaging technique for the detection of uterine masses requires additional validation on a larger number of patients and at multiple clinical sites. ${ }^{44}$

In conclusion, there seems to be limited diagnostic accuracy with saline infusion sonohysterography when better tolerated and more accurate imaging exists with ultrasonography (above) and MRI imaging (see below).

\section{Magnetic resonance imaging (MRI)}

Magnetic resonance imaging, while more costly, has been touted as the most sensitive modality for evaluating uterine myomas (Figure 3), particularly for the detection of small fibroids ${ }^{42}$ MRI is accurate in diagnosing a leiomyoma with a sensitivity of $88 \%-93 \%$ and a specificity of $66 \%-91 \%,{ }^{47,48}$ and in differentiating leiomyoma from focal adenomyosis. Thus, MRI is more sensitive in identifying uterine fibroids than ultrasound, does not involve the use of ionizing radiation, and it can readily demonstrate the uterine zonal anatomy. ${ }^{37,42,49}$ Submucosal, intramural, and subserosal 

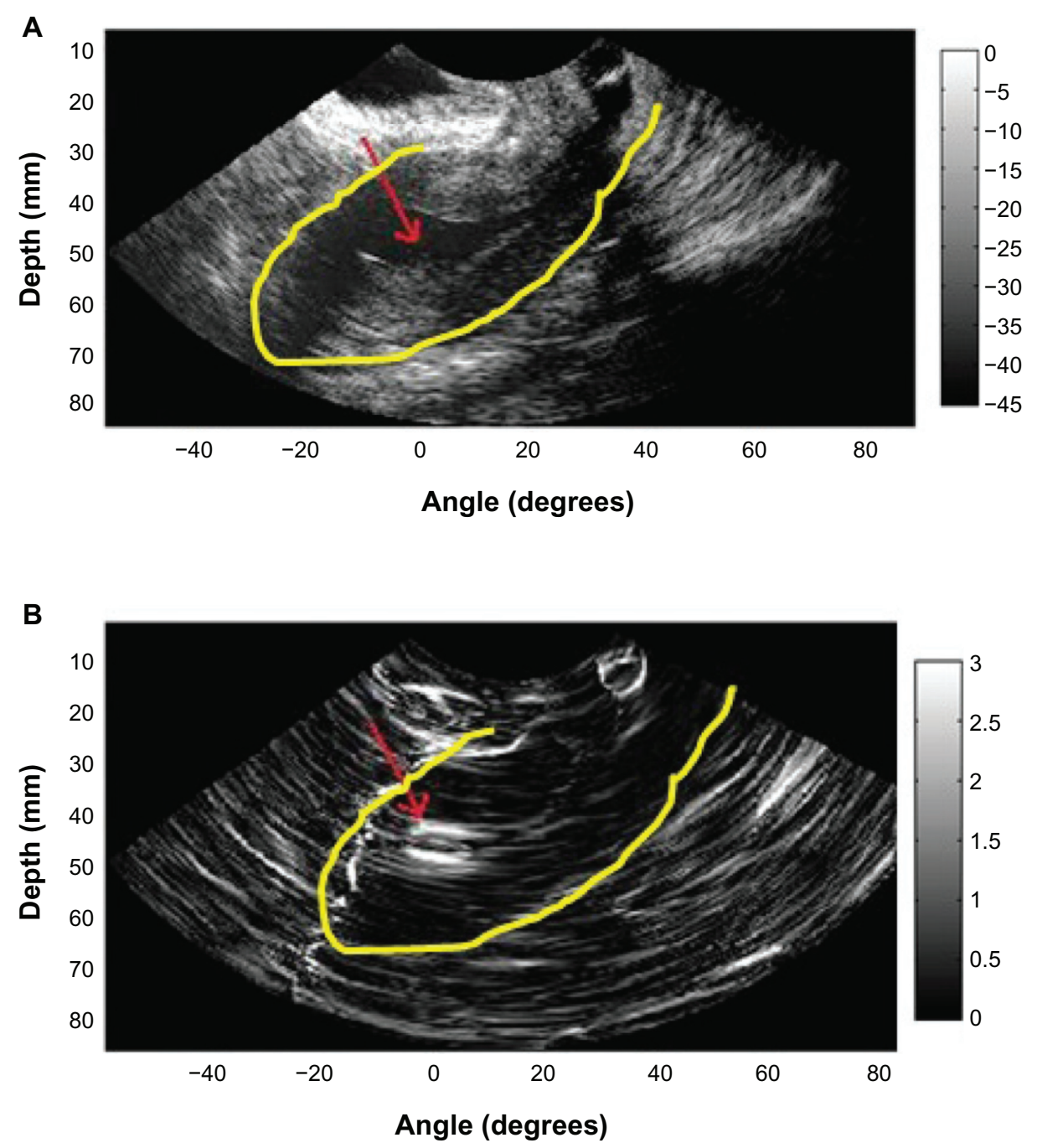

Figure 2 B-mode image (A) obtained during saline infusion sonohysterography in a 46-year-old woman with a diagnosis of an endometrial polyp and corresponding strain image (B) obtained using the 2-dimensional multilevel hybrid algorithm. Red arrows indicate the location of the polyp, and yellow contours indicate the outer uterine wall. Note: Republished with permission of American Institute of Ultrasound in Medicine, from A novel saline infusion sonohysterography-based strain imaging approach for evaluation of uterine abnormalities in vivo: preliminary results, Omari EA, Varghese T, Kliewer MA, 3 I (4) 20I2, permission conveyed through Copyright Clearance Center, Inc. ${ }^{44}$

fibroids are usually easily differentiated with MRI, and fibroids as small as $5 \mathrm{~mm}$ in diameter can be demonstrated. Fibroids in relatively unusual locations, such as within the cervix, can also be identified..$^{40}$ MRI can be very helpful when investigating suspected acute fibroid complications when the patient presents to the emergency department, ${ }^{50}$ and it is also a valuable tool that can be used to both predict and assess the response of fibroids to uterine artery embolization (UAE) ${ }^{40}$ Uterine fibroids are composed of a combination of smooth muscle cells and fibrous connective tissue. As these masses enlarge, they commonly outgrow their blood supply and undergo varying degrees of necrosis, which accounts for their variable signal intensities on MRI. ${ }^{51}$ Typically, leiomyomas are low in signal intensity relative to their surrounding myometrium on $\mathrm{T} 2 \mathrm{~W}$ imaging and are isointense to myometrium on $\mathrm{T} 1 \mathrm{~W}$ imaging. ${ }^{52,54}$ These signal characteristics are related to the most common form of degeneration $(60 \%)$, which is hyalinization throughout the leiomyoma. ${ }^{53,54}$ Weinreb et al defined diagnostic criteria for a leiomyoma to include a uterine mass that is predominantly hypointense compared to the myometrium on $\mathrm{T} 2 \mathrm{~W}$ imaging and predominantly hypointense on $\mathrm{T} 1 \mathrm{~W}$ imaging. ${ }^{43}$

In some instances, it can be difficult to differentiate a large exophytic, subserosal leiomyoma from a solid adnexal mass such as an ovarian neoplasm. Differentiation is clinically very important because of differences in treatment and prognostic implications. MRI in combination with the patient's clinical findings can be invaluable in making this distinction and can avoid unnecessary laparoscopy and/or exploratory surgery. ${ }^{51}$ Location is an important distinguishing characteristic. If the mass can be definitively separated from the ovaries or is contiguous with the round ligament, then an ovarian etiology is unlikely. 
A well-described MRI feature that is helpful in the evaluation of large pelvic masses has been referred to as the 'bridging vascular sign, ${ }^{55}$ which consists of vessels and/or signal voids that extend from the uterus to supply a pelvic mass. The identification of the bridging vascular sign increases the diagnostic confidence that a large pelvic mass is a uterine leiomyoma. ${ }^{55}$ The bridging vessels can be identified as enhancing tubular structures on contrast-enhanced T1W imaging or as flow voids on a T2W fast spin-echo sequence. ${ }^{51}$ In a study by Kim et al, the bridging vascular sign was present in 20 out of 26 exophytic leiomyomas and was absent in all other adnexal masses, resulting in a diagnostic accuracy of $80 \% .^{55}$

Fibroids that have undergone acute degeneration show great diversity in their MRI appearances with cystic change and areas of non-enhancement. In cases of red degeneration, the patient often presents with an acute abdomen. The use of multiplanar views can enable localization of fibroids and can make it possible to distinguish fibroids from acute presentations of ovarian masses. MRI appearances show high signal intensity centrally within the fibroid on T1-weighted images consistent with blood, with reduced signal at the periphery on T2-weighted images secondary to hemosiderin deposition. ${ }^{50}$ There may be heterogeneous signal intensity on T2, with no enhancement post-gadolinium administration (although gadolinium is not given to pregnant patients). ${ }^{54,56}$

Fibroids that demonstrate high signal on T1W images prior to embolization are likely to have a poor response to UAE as they may already have outgrown their blood supply and undergone hemorrhagic necrosis. ${ }^{40}$ Conversely, high signal on T2W images prior to embolization has been shown to be a predictor of good response. ${ }^{57}$ The vascularity of a fibroid is demonstrated by gadolinium enhancement and this is also a predictor of good response to UAE. Post-UAE fibroids typically show high signal on T1W images due to hemorrhagic necrosis. ${ }^{40}$

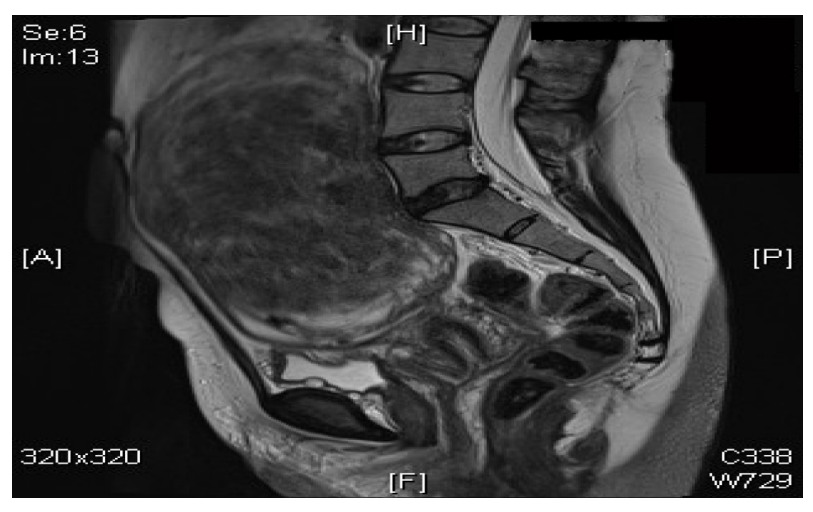

Figure 3 A 47-year-old woman with a hugely enlarged uterus. The fundus is at the level of $L 3$. It contains a solitary large intramural fibroid which is mostly right sided, displacing the cavity to the left. This fibroid measures approximately $14.2 \times 10.9 \times 8.8 \mathrm{~cm}$.

\section{Management Conservative}

Management of a patient with uterine fibroids is highly dependent on the presentation and patient wishes. Other causes of abnormal uterine bleeding, pelvic pressure/pain, and subfertility usually need to be ruled out beforehand. In many cases, the management of the fibroids carries surgical risks, and in some women, the fibroids are best left alone. Women with symptoms who have small fibroids but are close to menopause or who are trying to conceive should be offered conservative treatment with analgesics and hematinics. ${ }^{58}$

Because fibroids are so common in women, it is almost a disservice to call leiomyomata a pathologic entity. ${ }^{59}$ In several studies, women with minimal or no symptoms had no change in quality of life or symptomatology when they were conservatively managed; thus, prophylactic treatment is unwarranted..$^{60,61}$

\section{Medical}

At present, medical treatments are only used for short-term therapy because of the significant risks with long-term therapy, or lack of evidence regarding the benefits and risks of long-term therapy with the newer medical agents. They may be used or are used in the following situations:

- as 'stand-alone' treatment for temporary relief of symptoms for short periods. This application is suitable in women with symptomatic fibroids in the peri-menopausal years or in patients not suitable for surgery due to medical reasons;

- as a pre-operative adjunct to reduce the size of fibroids, to control bleeding, and to improve hemoglobin levels. The reduction in fibroid size may also convert a technically difficult procedure to an easier procedure (eg, abdominal hysterectomy to vaginal hysterectomy). They can be used before myomectomy, hysterectomy, and hysteroscopic submucous resection of fibroids. At present, gonadotrophin-releasing hormone analogs ( $\mathrm{GnRHa})$ are mainly used for this purpose; and

- in research, as part of an evaluation of new potential therapies. ${ }^{3}$

\section{Antifibrinolytics agents (tranexamic acid)}

Used only during the menstrual cycle, tranexamic acid has been associated with up to a $50 \%$ decrease in bleeding in women with menorrhagia, ${ }^{62}$ but there are few studies on women with leiomyomas. One study found no difference in blood loss with tranexamic acid therapy but had a sample size 
of 12 women with leiomyomas. ${ }^{63}$ Thrombotic risk was found to be similar to that of other menorrhagia treatments. ${ }^{64}$ There is retrospective evidence of increased necrosis in leiomyomas among tranexamic acid users. ${ }^{65}$

\section{Combined oral contraceptive (COC) and progestins}

Combined oral contraceptive (COC) hormones have been widely trialed by physicians to reduce the blood loss associated with uterine fibroids. ${ }^{66} \mathrm{~A}$ large prospective study including more than 3,000 patients with fibroids found a positive correlation between the early use of COCs (before 17 years) and the incidence of fibroids. ${ }^{67}$ Other controlled trials showed no association between the use of COCs and the development of uterine fibroids. ${ }^{68,69}$ The effect of COCs and progestins in reducing the size of fibroids is not documented..$^{70-72}$

\section{Mirena ${ }^{\circledR}$ IUS}

The levonorgestrel intra-uterine device (LNG-IUS) (Mirena) is effective in reducing menstrual blood loss and should be considered as an alternative to surgical treatment. ${ }^{73}$ The LNG-IUS has been shown to reduce menstrual blood loss by $94 \%$ over 3 months, and is well accepted by most women when used in the general population of women with menorrhagia. ${ }^{74}$

At present, there are no randomized controlled trials (RCTs) on the effect of LNG-IUS in menorrhagic women with uterine myomas. There are, of course, reports of its use in these women, with striking reductions in menorrhagia being reported. ${ }^{75}$ Although some women with large intramural myomas had spontaneous expulsion of the LNG-IUS at various intervals, they wanted re-insertion of the device because of remarkable reduction in menorrhagia. ${ }^{76}$ Significant increases in hemoglobin levels in blood were observed after insertion of the LNG-IUS, but no significant differences were noted in myoma volume and uterine volume, as assessed by MRI between pre-treatment and 12 months of use. ${ }^{75,76}$ There is therefore an obvious need for further research in this area. ${ }^{77}$ It would be interesting to establish whether expulsion of the device is dependent upon the size, number, or location of the fibroids; it is reasonable to assume that submucous fibroids, or large intramural fibroids distorting the cavity, are likely to be associated with an increased risk, but definitive studies need to be undertaken in order to provide the evidence base to better advise patients.

\section{GnRH analogs (GnRHa)}

GnRHa alone or more commonly with 'add-back therapy', are frequently used as temporizing measures in perimenopausal women, or pre-operatively to reduce fibroid size and render surgery safer/easier. A single injection of GnRHa produces an initial stimulation of pituitary gonadotrophins, resulting in increased secretion of follicle-stimulating hormone (FSH) and $\mathrm{LH}$ and the expected gonadal response. However, continuous or repeated administration of GnRHa in a continuous (non-pulsatile) fashion or administration of supraphysiological doses ultimately produces inhibition of the pituitary-gonadal axis.

GnRHa undoubtedly induce fibroid tumor shrinkage, the degree of which has been shown to be directly proportional to the percentage of cells that are estrogen receptor positive, thus implicating estrogen as a major effector of tumor growth and its reduction as the central mechanism of fibroid shrinkage with GnRHa therapy. ${ }^{78}$ Chegini et al found evidence of suppression of signal transduction pathways involving growth factors, ovarian steroids, and adhesion molecules with a resulting decrease in DNA synthesis, cell proliferation, and production of transforming growth factor-b. ${ }^{79,80}$ They found that medical treatment causes altered regulation in a number of genes involved in the regulation of cell growth, signal transduction, transcription factors, and cell structures. ${ }^{81}$ Therapy with leuprolide acetate has been associated with hyalization of leiomyomata ${ }^{82}$ and decreases in uterine or tumor arterial size and blood flow variables. ${ }^{83-85}$

A Cochrane Systematic Review ${ }^{86}$ to evaluate the role of GnRHa prior to either hysterectomy or myomectomy showed that pre- and postoperative hemoglobin and hematocrit were improved significantly by the use of GnRHa prior to surgery. Uterine volume and size, fibroid volume and pelvic symptoms were all reduced. Hysterectomy was rendered easier, with reduced operating time, and a greater proportion of hysterectomy patients were able to have a vaginal rather than an abdominal procedure. Blood loss and rate of vertical incision were reduced for both myomectomy and hysterectomy. Duration of hospital stay was also reduced. The disadvantages of GnRHa include cost, menopausal symptoms, and with prolonged therapy, bone demineralization. In addition, smaller fibroids may be overlooked at the time of surgery, only to recur once GnRHa is discontinued (thereby increasing the apparent risk or recurrence of fibroids following myomectomy). GnRHa cannot be used as long-term standalone therapies for fibroid disease because of the rapid rebound growth of the fibroids upon cessation of therapy.

\section{Selective estrogen receptor modulators (SERMs)}

SERMs are non-steroidal estrogen receptor ligands that display tissue-specific agonist/antagonist estrogenic actions. ${ }^{66}$ 
They are most commonly used in the treatment and prevention of estrogen receptor-positive carcinoma of the breast; well-known examples being tamoxifen and raloxifene.

The most probable hypothesis that explains SERMs' mechanism of action is that they induce changes in estrogen receptors, which result in differential expression of specific estrogen-regulated genes in different tissues. ${ }^{87}$ Any molecule that blocks estrogen activity has the potential for therapeutic activity against fibroids, since estrogen is known to influence fibroid growth. SERMs are therefore within this category of molecule. However, because of its endometrial hyperplastic effect and case reports of fibroid growth following treatment, the potential of tamoxifen in the treatment of fibroids has not been investigated in RCTs. Raloxifene has been showed to enhance the shrinkage of uterine fibroids in postmenopausal women. ${ }^{88,89}$ However, a recent report from Italy that addressed the effect of raloxifene on uterine leiomyoma showed that the leiomyoma size in premenopausal women who were administered daily $60 \mathrm{mg}$ doses of raloxifene over a 2-year period exhibited no change in leiomyoma size..$^{90}$

\section{Selective progesterone receptor modulators (SPRMs)}

The effects of progesterone on target tissues are mediated via the progesterone receptor (PR), which belongs to the nuclear receptor family. ${ }^{91}$ Progesterone has dual actions on fibroid growth. It stimulates growth by upregulating epidermal growth factor (EGF) and Bcl-2 and downregulating tumor necrosis factor-alpha expression while it inhibits growth by downregulating insulin-like growth factor-1 (IGF-1) expression. While it has long been established that estrogen promotes fibroid growth, recent biochemical and clinical studies have suggested that progesterone and the PR may also enhance proliferative activity in fibroids. ${ }^{92,93}$ These observations have therefore raised the possibility that anti-progestins and agents or molecules that modulate the activity of the PR could be useful in the medical management of uterine fibroids (Figure 4). Since the emergence of mifepristone (RU-486), the first PR antagonist, more than 25 years ago, hundreds of steroidal as well as non-steroidal compounds displaying progesterone antagonist (PA) or mixed agonist/antagonist activity have been synthesized. Collectively, they are known as progesterone receptor modulators (PRMs). Some of the PRMs which have been the subject of recent clinical trials or research studies in relation to fibroid treatment include mifepristone, CDB-4124 (telapristone), CP-8947, J867 (asoprisnil), and CDB-2914 (ulipristal acetate). ${ }^{94}$
A number of clinical trials have established the potential of SPRMs in the treatment of uterine fibroids. They are associated with a reduction in pain, bleeding, size of fibroids, and overall improvement in quality of life. Unlike long-acting GnRH analogs, they do not have the drawbacks of profound estrogen deficiency and decrease in bone mineral density. ${ }^{94}$

\section{Mifepristone}

Early reports of the use of mifepristone for the treatment of fibroids date back to 2002, when De Leo et al used doses ranging from 12.5 to $50 \mathrm{mg}$ daily and reported a reduction in uterine/fibroid volume of $40 \%-50 \%$, with amenorrhea in most subjects. ${ }^{95}$ This report was corroborated by a paper a year later from a group who used mifepristone at a dose of 5 or $10 \mathrm{mg}$ per day for 1 year, and found that it was effective in decreasing mean uterine volume by $50 \%$, while amenorrhea occurred in $40 \%-70 \%$ of the subjects. ${ }^{96}$ Endometrial hyperplasia was seen in some women on mifepristone which limited the long-term use of this drug among those desiring a medical therapeutic alternative. The apparent effectiveness of mifepristone, however, in reducing myoma volume and improving fibroid-related symptoms and quality of life, and the minimal side effects, all point to a need for a large RCT with sufficient power to define its true place in the medical management of uterine fibroids. A combination of mifepristone and the LNG-IUS could prove especially useful as the IUS would obviate the development of endometrial hyperplasia while also promoting a reduction in menstrual flow. ${ }^{94}$ In another RCT, 100 women were assigned to mifepristone 5 or $10 \mathrm{mg}$ daily for 3 months without a placebo group: with both doses, there were equivalent reductions in fibroid and uterine volumes and symptomatic improvements. ${ }^{97}$

\section{Ulipristal acetate}

Ulipristal acetate (UA) has recently successfully completed two Phase III clinical trials (PEARL [PGL 4001's Efficacy Assessment in Reduction of symptoms due to uterine Leiomyomata] I and II) in Europe, demonstrating its efficacy and safety for the treatment of symptomatic uterine fibroids in patients eligible for surgery. ${ }^{94}$ PEARL I compared treatment with oral UA for up to 13 weeks at a dose of $5 \mathrm{mg}$ per day (96 women) or $10 \mathrm{mg}$ per day (98 women) with a placebo (48 women) in patients with fibroids, menorrhagia, and anemia. Treatment with UA for 13 weeks effectively controlled excessive bleeding due to uterine fibroids and reduced the size of the fibroids. ${ }^{98}$ PEARL II was a double-blind, non-inferiority trial, which randomly assigned 307 patients with symptomatic 


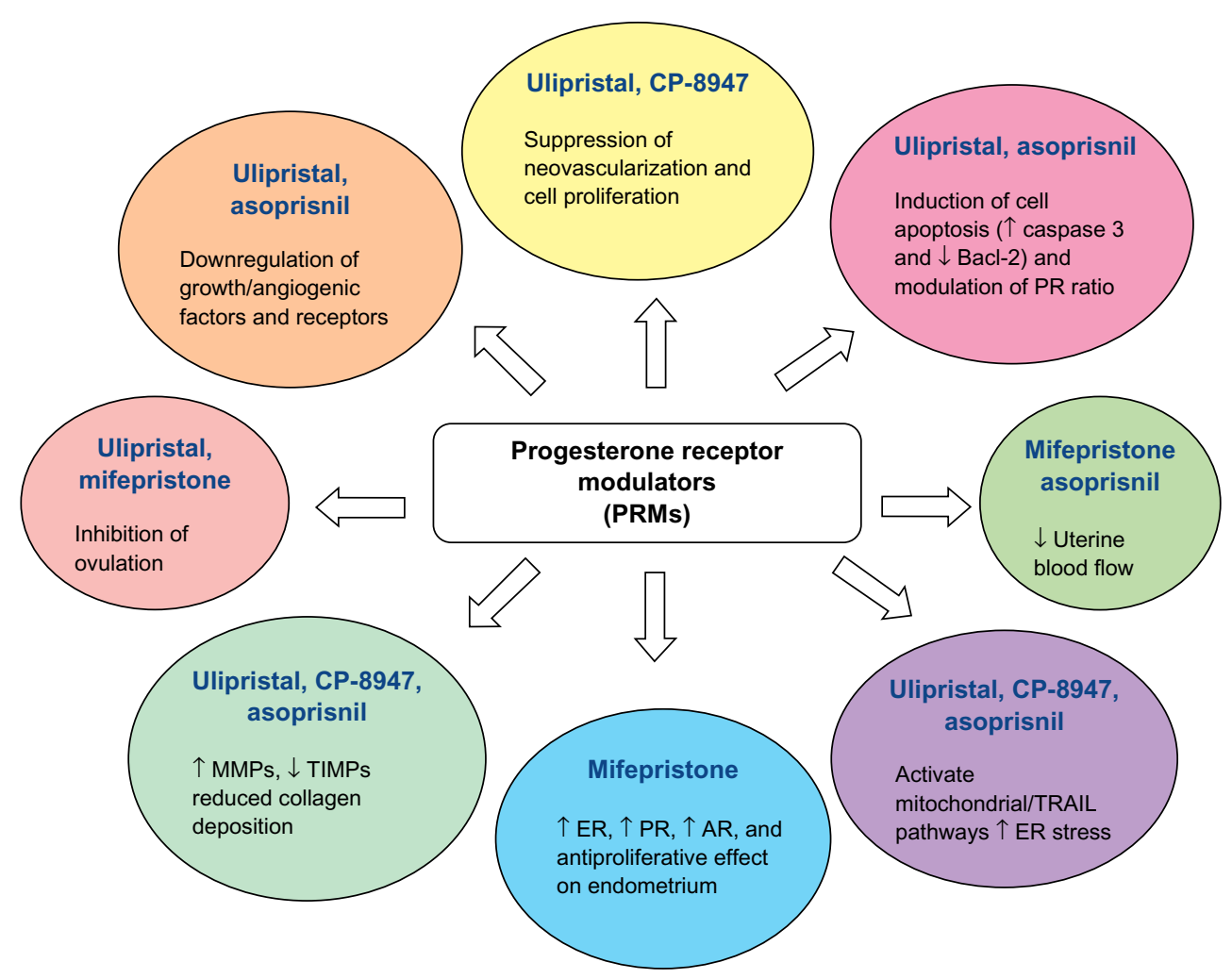

Figure 4 Mechanisms of action of progesterone receptor modulators on uterine fibroids.

Note: Reprinted from Eur J Obstet Gynecol Reprod Biol, 165, Talaulikar VS, Manyonda I, Progesterone and progesterone receptor modulators in the management of symptomatic uterine fibroids, I35-140, Copyright 2012, with permission from Elsevier. ${ }^{94}$

Abbreviations: ER, estrogen receptors; PR, progesterone receptors; AR, androgen receptors; TRAIL, TNF-related apoptosis-inducing ligand; MMP, matrix metalloproteinases; TIMP, tissue inhibitors of metalloproteinases.

fibroids and excessive uterine bleeding to receive three months of daily therapy with oral UA (at a dose of either $5 \mathrm{mg}$ or $10 \mathrm{mg}$ ) or once monthly intramuscular injections of the $\mathrm{GnRH}$ analog leuprolide acetate (at a dose of $3.75 \mathrm{mg}$ ). Uterine bleeding was controlled in $90 \%$ of patients receiving $5 \mathrm{mg}$ of UA, in $98 \%$ of those receiving $10 \mathrm{mg}$, while the figure for leuprolide acetate was $89 \%$. Both UA doses were non-inferior to once monthly leuprolide acetate in controlling uterine bleeding and were significantly less likely to cause hot flushes. ${ }^{99}$

Clinicians detecting endometrial thickening in women treated with SPRMs need to be aware that administration of SPRMs for longer than 3 months may lead to endometrial thickening. This is related to cystic glandular dilation, not endometrial hyperplasia, and pathologists need to be aware of PRM-associated endometrial changes (PAEC) and avoid misclassifying the appearance as hyperplasia. It is also important to consider the limitations of the current data while describing the effects of SPRMs on the endometrium. Most existing studies have described the endometrial changes over short periods (months) of follow-up, but atypical hyperplasia and possibly malignant change take years to develop. Long-term studies are therefore necessary to evaluate such outcomes. ${ }^{94}$

\section{Aromatase inhibitors}

Aromatase inhibitors (AI) significantly block both ovarian and peripheral estrogen production within 1 day of treatment. ${ }^{100}$ The underlying mechanism is the inhibition of the aromatase enzyme, an enzyme that catalyzes the conversion of androgenic substances into estrogens. ${ }^{101}$ Recent reports have suggested that aromatase is expressed to a greater extent in uterine leiomyoma tissues of African-American women compared to Caucasian women, which may contribute to the higher incidence of fibroids in African-American women. ${ }^{102}$ Aromatase inhibitors have been shown to be effective against fibroids in limited short-term studies with dosing regimens that included $2.5 \mathrm{mg}$ per day of letrozole and $1 \mathrm{mg}$ per day of anastrozole. ${ }^{103}$ One of the major concerns with the use of aromatase inhibitors is the reported bone loss with prolonged use, which necessitates the concomitant use of oral contraceptive pills or progesterone. ${ }^{104} \mathrm{~A}$ recently published RCT compared the effects of 3 months of aromatase inhibitor (letrozole) to that of 3 months of gonadotropin-releasing hormone agonist (triptorelin) on uterine leiomyoma volume and hormonal status. The results showed an advantage of the rapid onset of action of AIs in addition to the avoidance of the flare-ups that 
initially occur with GnRHa. Both treatment options induced significant shrinkage of the uterine fibroids and improvement in leiomyoma-associated symptoms. ${ }^{105}$ The mean reduction of leiomyoma volume with 3 months' use of anastrazole is $55.7 \% .{ }^{106}$ Several RCTs are underway that would hopefully add to our understanding of the potential promising role of AIs in the treatment of uterine leiomyomas. ${ }^{107}$

\section{Somatostatin analogs}

Increasing evidence has demonstrated a role for growth factors, such as insulin growth factor I (IGF-I) and IGF-II, in the initiation and progression of uterine fibroids. ${ }^{108-111}$ Leiomyoma tissue expresses higher levels of IGF-I/IGF-II receptors compared to normal adjacent myometrium. ${ }^{110,112}$ It has recently been reported that acromegalic patients have a higher prevalence of uterine fibroids than the general population. ${ }^{113}$ Lanreotide, which is a long-acting somatostatin analog that has been shown to reduce growth hormone secretion, has also recently been evaluated in seven women with uterine fibroids in Italy. ${ }^{114}$ Interestingly, lanreotide induced a $42 \%$ mean myoma volume reduction within a 3-month period. These results show that somatostatin analogs may potentially be a new therapy for uterine fibroids. ${ }^{115}$ The treatment with somatostatin analogs for diseases other than leiomyoma appears to be safe and is usually well-tolerated with some reports of gallstone formation. ${ }^{116,117}$ However, the lack of clinical trials which test the long-term use of somatostatin analogs along with the severe and adverse health implications such as decreased life expectancy due to accelerated heart disease which was observed in adults with growth hormone deficiency may hinder its future use for leiomyoma treatment. $^{66}$

\section{Other hormonal agents}

A preliminary study published in 2007 favored the use of cabergoline as a medical treatment of uterine fibroids. The authors reported a volume reduction of about $50 \%$ with 6 weeks' use. ${ }^{118}$ The same group performed a subsequent study that compared cabergoline with diphereline, which is a gonadotropin-releasing hormone agonist. They reported comparable results in terms of the shrinkage of the fibroids and improvement in the sonographic, clinical, and intraoperative outcomes. ${ }^{119}$

Gestrinone is a steroid that possesses anti-estrogen receptor and anti-progesterone receptor properties in various tissues, including the endometrium. A recent report from Italy evaluated the use of gestrinone in the treatment of premenopausal women with uterine fibroids. The authors reported a $32 \% \pm 10 \%$ reduction in uterine volume. ${ }^{120} \mathrm{~A}$ subsequent study reported up to $60 \%$ leiomyoma shrinkage in size. ${ }^{121}$ Gestrinone is a contraceptive agent and also exhibits several unfavorable side effects, such as mild androgenicity, weight gain, seborrhea, acne, hirsutism, and occasional hoarseness. ${ }^{66}$

\section{Vitamin D}

There is evidence that Vitamin D is an anti-fibrotic factor and inhibits growth and induces apoptosis in cultured human leiomyoma cells through the downregulation of proliferating cell nuclear antigen (PCNA), cyclin-dependent kinase 1 (CDK1), and B-cell lymphoma 2 (BCL-2) and suppresses catechol-O-methyl transferase (COMT) expression and activity in human leiomyoma cells. ${ }^{122,123}$ A study observed that 1,25-dihydroxyvitamin D3 is significantly lower in women with fibroids compared to normal healthy controls; additionally, lower levels of total serum 25-hydroxyvitamin D3 have been detected in women with fibroids compared to healthy controls. The aim of this study was to determine whether serum levels of Vitamin D correlated with disease severity in women with symptomatic uterine fibroids. The study population consisted of 67 patients who had detailed repeated pelvic ultrasound evaluations over a 2-year period with specific measurements of the total uterine volume and the volume of the individual leiomyoma lesions. The patients also had detailed laboratory analysis including serum 25-hydroxyvitamin D3 levels. Preliminary results have suggested a strong dose-response correlation between lower serum vitamin D levels and increased severity of uterine fibroids. This presents an opportunity for the potential use of vitamin $\mathrm{D}$ or its potent analogs as novel treatment options or for the prevention of uterine fibroids. ${ }^{124,125}$

\section{Epigallocatechin gallate (EGCG) - green tea extract}

A typical green tea beverage, prepared in a proportion of $1 \mathrm{~g}$ leaf to $100 \mathrm{~mL}$ water with a 3-minute brew, usually contains 250-350 mg tea solids, and catechins account for $30 \%-42 \%$ of the dry weight of the solids. ${ }^{126}$ The major green tea catechins are epigallocatechin-3-gallate (EGCG), epigallocatechin (EGC), epicatechin-3-gallate (ECG), and epicatechin. Catechins are a group of bioflavonoids that exhibit antioxidant and anti-inflammatory capacity. ${ }^{127}$ EGCG appears to block each stage of tumorgenesis by modulating signaling pathways involved in cell proliferation, transformation, inflammation, and oxidative stress, which are clearly involved in pathogenesis of various tumors including uterine fibroids. ${ }^{128}$ The potential effect and 
mechanisms of EGCG action on human leiomyoma (HuLM) cells was studied and it was found that EGCG inhibits the proliferation of HuLM cells and induces apoptosis. These results suggest that EGCG may be a potential anti-uterine fibroid agent acting through multiple signal transduction pathways. ${ }^{129}$

\section{Minimally invasive techniques}

Even women without a desire for future pregnancies might not wish to lose their uterus for various reasons. In the past years, several nonsurgical and minimally invasive treatment options have been introduced and studied, which not only preserve the uterus and thereby fertility, but also reduce morbidity and recovery time in comparison with hysterectomy. Although hysterectomy is the only definitive solution, many women and doctors seek the possibility of minimally invasive uterus-sparing alternatives for the treatment of uterine fibroids. ${ }^{130}$ Some of these therapies include uterine artery embolization (UAE), MRgFUS (magnetic resonanceguided focused ultrasound surgery) and ultrasound-guided ablation (VizAblate ${ }^{\mathrm{TM}}$ [Gynesonics, Redwood City, CA, USA] and Acessa ${ }^{\mathrm{TM}}$ [Halt Medical, Inc., Brentwood, CA, USA] Procedures).

\section{Uterine artery embolization (UAE)}

UAE is a percutaneous, image-guided procedure which is performed by a properly trained and experienced interventional radiologist. ${ }^{131}$ In the past, embolization was used to reduce pelvic bleeding. ${ }^{132}$ Only since 1995 has UAE been seen as a potential treatment for menorrhagia related to uterine fibroids. ${ }^{133,134}$ In essence, it involves the placement of an angiographic catheter into the uterine arteries via a common femoral artery approach and injection of embolic agents (in most cases, polyvinyl alcohol particles or trisacryl gelatin microspheres) into both uterine arteries until the flow becomes sluggish (Figure 5). ${ }^{135-141}$ The proposed mechanism of UAE's action is by occluding or markedly reducing uterine blood flow at the arteriolar level to produce an irreversible ischemic injury to the fibroids, causing them to undergo necrosis and shrink, while the normal myometrium is able to recover. ${ }^{142,143}$

The procedure, which is usually performed under local anesthetic or intravenous conscious sedation, generally requires 1 hour to complete. With operator experience and proper technique, patient radiation exposure during UAE is comparable to that received during routine diagnostic imaging procedures. ${ }^{144-147}$

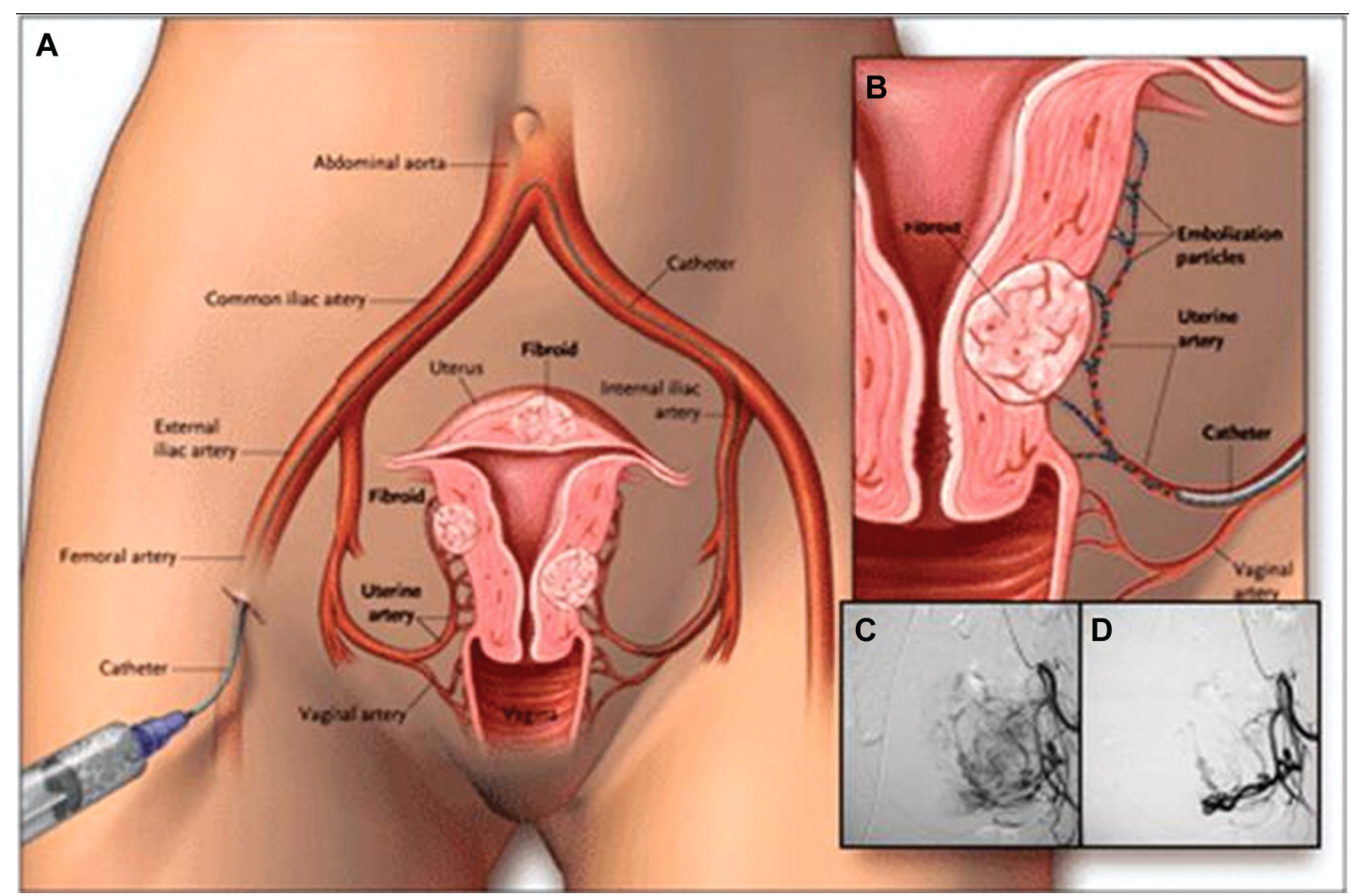

Figure $\mathbf{5}$ The UAE procedure. Drawings (A and $\mathbf{B})$ illustrate the path of the catheter to deliver embolization particles to occlude the uterine arteries. Angiograms show the fibroid blood supply before (C) and after (D) UAE.

Note: Reproduced from Tropeano G, Amoroso S, Scambia G. Non-surgical management of uterine fibroids. Hum Reprod Update. 2008; 14(3):259-274, by permission of Oxford University Press. ${ }^{153}$

Abbreviation: UAE, uterine artery embolization. 
Immediately after the end of the procedure, most patients experience moderate-to-severe ischemic pain for $8-12$ hours - usually requiring parenteral analgesia (narcotics and non-steroidal, anti-inflammatory drugs), but pain severity gradually decreases after 12 hours, ${ }^{148}$ and a day-case or overnight stay is required at most. Recovery is typically brief and relatively mild, with $4-5$ days of recurrent uterine cramping and constitutional embolization symptoms (generalized malaise, fatigue, nausea, and low-grade fever). Patients can usually return to normal activities within 8-14 days. ${ }^{139,149-152}$

UAE is not without its own set of complications. They can be divided into immediate (occurring during the procedure), early (within the first 30 days), and late (beyond the first 30 days). Immediate complications include hematoma formation, thrombosis, or pseudo-aneurysm. Reaction to the contrast media is unusual. Failure to cannulate the uterine artery can occur in a very small percentage of patients. Early complications include 'post-embolization syndrome' which can occur commonly, although it is only severe in a minority of cases. It consists of pain, nausea, a flu-like illness, mild pyrexia, and raised inflammatory markers. If the symptoms are prolonged or the patient is becoming very ill then infection must be suspected. Significant infection is less common than was originally predicted, which is fortunate as hysterectomy performed soon after uterine artery embolization tends to be a very difficult procedure. Vaginal discharge is common and usually settles down within a few days. Late complications include chronic vaginal discharge, adverse changes in sexual function, and temporary amenorrhea. The incidence of amenorrhea is related to the age of the woman and is particularly common in those over 45 years of age. Fibroid expulsion can occur in $10 \%$ of cases and is particularly common with submucous fibroids. Occasionally, operative intervention is required but usually if the patient is warned that this might occur then no further treatment is required. ${ }^{154}$

A recently published Cochrane review ${ }^{155}$ has looked at the benefits and risks of UAE versus other medical or surgical interventions for symptomatic uterine fibroids. It found that there was no significant difference in satisfaction rates between the two groups in spite of a higher rate of postprocedural complications and further re-interventions in the UAE arm of the study. There was only one study which specifically looked at the impact of UAE versus myomectomy on fertility, an important parameter as both are uterine-sparing procedures. ${ }^{156,157}$ The findings for live birth were of borderline statistical significance, favoring myomectomy, and there were significantly more pregnancies in the myomectomy group. Not all the women in the study were trying to conceive: 26 after UAE and 40 after myomectomy. The pregnancy rate after UAE was $50 \%$, delivery rate $19 \%$, and miscarriage rate $53 \%$, while these percentages were $78 \%, 48 \%$, and $23 \%$, respectively, after myomectomy. The differences in all these parameters were statistically significant $(P<0.05)$. UAE was advantageous over hysterectomy or myomectomy with regards to a shorter hospital stay, a quicker return to full activity, and reduced likelihood of a need for blood transfusion. However, UAE was associated with an increased short-term risk of minor complications. The REST (Multicentre Randomised controlled trial comparing uterine artery Embolisation with Surgical Treatment for uterine fibroids) study ${ }^{158}$ looked at complications over five years and again the rate of minor complications was higher in the UAE group. No study found a significant difference between the groups in major complications in either short- or long-term follow-up.

In the previous version of this Cochrane review, the authors had concluded that the women opting for UAE should be counseled about a higher surgical intervention rate in the longer term. This has been supported by the 5-year follow-up data from the EMMY (EMbolization versus hysterectoMY) ${ }^{159}$ and REST trials. There is a five-fold increase in the likelihood of needing further intervention after UAE. However, satisfaction rates were similar in both the groups. Although UAE initially appears to be a cost-effective alternative to hysterectomy, the long-term follow-up at 5 years shows that this advantage is lost due to a subsequent higher rate of re-intervention. ${ }^{158,159}$

The effect of UAE on ovarian reserve and pregnancy outcome is less well established. ${ }^{130} \mathrm{FSH}$ levels as an indicator of ovarian failure after 2 years were not significantly different between UAE and surgery. ${ }^{155}$ Another systematic review ${ }^{160}$ showed that miscarriage rates were higher in post-UAE pregnancies (35.2\%) compared with pregnant women with a non-treated fibroid uterus, matched for age, and fibroid location $(16.5 \%)$. The UAE pregnancies were more likely to be delivered by cesarean section and to experience postpartum hemorrhage. Rates of preterm delivery, intrauterine growth restriction, and malpresentation were similar in UAE pregnancies and in control pregnancies with fibroids.

\section{Magnetic resonance-guided focused ultrasound surgery (MRgFUS)}

MRgFUS is a relatively new method of thermal ablation for treating fibroids, which uses high-intensity focused ultrasound that passes through the anterior abdominal wall and converges into a precise target point within the fibroid to cause a temperature rise $\left(55^{\circ} \mathrm{C}-90^{\circ} \mathrm{C}\right)$ sufficient to induce 
coagulative necrosis within a few seconds. Concurrent MRI allows accurate tissue targeting and real-time temperature feedback, thereby achieving controlled localized thermal ablation. ${ }^{161-163}$ The advantages of MRgFUS are its completely non-invasive character and continuous imaging of fibroids and adjacent structures, which optimizes fibroid ablation and prevents injury to adjacent tissues. ${ }^{164}$ The disadvantage is that relatively few patients are eligible - only those with fibroids located immediately beneath the anterior abdominal wall without bowel interposition or scars in the region of interest. The average treatment time is however, long and the patient has to lie still for the duration of the treatment time. ${ }^{165}$

The results of a prospective study ${ }^{166}$ into pregnancy outcomes after MRgFUS showed that the spontaneous miscarriage rate was $26 \%$, which was comparable with the rate in women of similar age without fibroids. ${ }^{167}$ Live births occurred in $41 \%$ of pregnancies, with an $11 \%$ rate of elective pregnancy termination, and $20 \%$ ongoing pregnancies beyond 20 gestational weeks the moment the study ended. The vaginal delivery rate was $64 \% .{ }^{166}$

At present, only a minority of women with uterine fibroids seems to meet the inclusion criteria for this new technique. Due to the lack of randomized data, MRgFUS should still be regarded as an experimental treatment. ${ }^{130}$

\section{Other ablation procedures} (VizAblate ${ }^{\mathrm{TM}}$ and Acessa ${ }^{\mathrm{TM}}$ )

With MRgFUS not being that widely available and having a long treatment time, a new transcervical device (VizAblate ${ }^{\mathrm{TM}}$ ) has recently been introduced that combines real-time intrauterine sonography with radiofrequency (RF) ablation for the treatment of fibroids. The fibroid ablation takes place under real-time visualization as an intrauterine sonography probe is built into the device. This built-in imaging removes the need for the physician to coordinate more than one device. The graphical interface delineates the boundaries of both ablation and thermal spread, enabling the gynecologist to avoid thermal injury to the serosa with its potential for adhesiogenesis and injury to bowel or bladder. Overall, the procedure is well-tolerated with low pain scores, allowing it to be considered for future use in the outpatient setting with local anesthetic or conscious sedation. Procedure time is in the range of 30 minutes. ${ }^{168}$

The novel use of radiofrequency ablation under laparoscopic and intra-abdominal ultrasound guidance to treat patients with symptomatic myomas was first introduced in 2002. ${ }^{169}$ This has prompted the development of the study device (Acessa ${ }^{\mathrm{TM}}$ ) which carries out laparoscopic ultrasoundguided radiofrequency volumetric thermal ablation of uterine myomas in symptomatic women. ${ }^{170}$ The key feature to using laparoscopic ultrasound lies in the inherent and immediate proximity of the transducer to the target (fibroid), allowing the use of higher frequencies with significantly increased resolution. In addition, the versatility and mobility of laparoscopic ultrasound permits direct imaging from multiple directions and angles. ${ }^{171}$ Based on a recent study, radiofrequency volumetric thermal ablation of uterine myomas safely achieved a high rate of patient satisfaction, a low re-intervention rate, and significant improvements in menstrual blood loss, symptom severity, and quality of life through 12 months of follow-up. ${ }^{170}$

\section{Surgical}

The standard treatment for symptomatic uterine fibroids has always been surgical, either hysterectomy or, in women who wish to preserve their fertility, the more conservative procedure of myomectomy. ${ }^{172}$ Fibroids represent one of the most frequent indications for major surgery in pre-menopausal women and as such, they constitute a major public health cost. ${ }^{173}$ Myomectomy can be carried out via hysteroscopy, laparoscopy, or classically as an abdominal procedure.

\section{Hysteroscopic myomectomy}

Submucosal fibroids can often be removed by hysteroscopic myomectomy. This can be performed under general or regional analgesia, and in some centers it is performed as an office procedure, depending on the type and the size of the fibroid(s). Although it is widely applied and its effect on bleeding complaints is well-known, there is surprisingly little randomized evidence to support this. ${ }^{130} \mathrm{~A}$ recent retrospective analysis of 105 patients that underwent hysteroscopic myomectomy for submucosal fibroids, showed the disappearance of bleeding symptoms in $90 \%$ of cases after a mean follow-up of 17 months. ${ }^{174}$ In a RCT, GnRH pre-treatment was found not to increase the number of complete resections. ${ }^{175}$

The most common perioperative complications associated with hysteroscopic myomectomy are hemorrhage $(2.4 \%)$, uterine perforation $(1.5 \%)$, cervical laceration $(1 \%-11 \%)$, and fluid overload by intravasation of distension fluid. Delayed complications from hysteroscopic surgery may include intrauterine adhesions and infertility. ${ }^{130}$ The average reported incidence is around $10 \%$ at second-look hysteroscopy, but it seems to be higher in certain conditions, for instance in the resection of multiple, opposing fibroids. ${ }^{176}$

A systematic review summarizing the effects of surgery on fertility showed that submucous fibroids or intramural fibroids with a submucosal component decreased clinical 
pregnancy and implantation rates, and removal of submucous fibroids led to a significant increase in pregnancy rate (from $27.2 \%$ to $43.3 \%$ ) and a decrease in miscarriage rate (from $50 \%$ to $38.5 \%) .{ }^{177}$

\section{Laparoscopic myomectomy}

Laparoscopic myomectomy has long been the minimally invasive therapy of choice for symptomatic uterine fibroids, before the introduction of UAE and other minimally invasive therapies. It is still widely used for symptomatic subserosal fibroids and can even be used for intramural fibroids, depending on the position of the fibroid and the skills of the surgeon. ${ }^{130}$ A prospective study with 235 patients undergoing laparoscopic myomectomy for symptomatic fibroids showed no conversions to laparotomy and in 3 years, only $1.2 \%$ of patients had a second laparoscopic myomectomy for recurrent fibroids. By 48 hours after surgery, $86.3 \%$ of the patients were discharged. ${ }^{178}$ A systematic review compared women with subserosal fibroids to women without fibroids, and found no difference for fertility outcomes. In contrast, women with intramural fibroids had significantly lower clinical pregnancy rates and ongoing pregnancy/live birth rates and significantly higher spontaneous miscarriage rates compared with women without fibroids. The same review could not identify a significant effect of the removal of intramural fibroids on fertility outcomes, as compared between women with intramural fibroids and women that underwent removal of their intramural fibroids. ${ }^{177,179}$

Blood loss is an important clinical problem during myomectomy. A Cochrane review found significant reductions in blood loss with misoprostol, vasopressin, bupivacaine and epinephrine, tranexamic acid, peri-cervical tourniquet, and gelatin-thrombin matrix. There was no evidence of an effect on blood loss with oxytocin. ${ }^{180}$

\section{Abdominal myomectomy}

A cohort study compared perioperative morbidity between women who underwent abdominal myomectomy or abdominal hysterectomy. It reported no significant difference in overall morbidity between the two groups (39\% versus $40 \%$, odds ration [OR]: 0.93; 95\% confidence interval [CI]: 0.63-1.40). There was significantly lower prevalence of hemorrhage and performance of an unintended procedure in the myomectomy group than in the hysterectomy group. Abdominal myomectomy was a lengthier procedure but was associated with significantly less blood loss. The average hospital stay was significantly shorter in the myomectomy group. Overall, no clinically significant difference in perioperative morbidity between myomectomy and hysterectomy was detected. Myomectomy may be considered a safe alternative to hysterectomy. ${ }^{181}$

A recent observational study has suggested that abdominal myomectomy might improve reproductive outcomes in patients with myomas. The reproductive performance was particularly good when the patients were younger and had previous pregnancies prior to the surgery. Myomectomy is associated with lower miscarriage rate after pregnancy, compared to those prior to the surgery. ${ }^{182}$

\section{Hysterectomy}

The first successful selected hysterectomy operation was performed in 1813 by Conrad Langenbeck via the vaginal approach, ${ }^{183}$ and today, after nearly two centuries, hysterectomy is the second most frequent surgery in women of reproductive age, with the first being cesarean section. ${ }^{184}$ Approximately 55,000 hysterectomies are performed each year in the UK, and over 600,000 in the USA. ${ }^{185,186}$ The vast majority of these numbers (more than 70\%) are for benign indications such as menorrhagia (21\%), fibroids (33\%), pelvic pain $(3 \%)$, and uterine prolapse $(28 \%) .{ }^{186}$

Hysterectomy is the definitive procedure and carries an outstandingly good outcome and guarantees complete cessation of periods with no risk of fibroid recurrence. Hysterectomy can be done via the vaginal, abdominal, or laparoscopic (total or laparoscopic-assisted vaginal) route. Each carries its own advantages and disadvantages. The traditional surgical approach to hysterectomy involves a large abdominal incision, 2-5 day hospital stay, and significant requirements for postoperative analgesia. Laparoscopic techniques have many advantages over laparotomy, including reduced postoperative pain, shorter length of hospital stay, better cosmesis, and quicker resumption of regular activity. ${ }^{183}$

National Institute for Health and Care Excellence (NICE) guidelines recommend that hysterectomy should be considered only when other treatment options have failed, are contraindicated or are declined by the woman, there is a wish for amenorrhea, the woman (who has been fully informed) requests it, and the woman no longer wishes to retain her uterus and fertility. ${ }^{187}$ Most importantly, hysterectomy carries some serious risks including damage to the bowel, bladder and/or ureter, hemorrhage requiring blood transfusion, return to theatre because of bleeding/wound dehiscence, pelvic abscess/infection, and venous thrombosis or pulmonary embolism. ${ }^{188}$

\section{Leiomyosarcomas of the uterus}

Uterine leiomyosarcoma is a rare neoplasm with an annual incidence of 0.64 per 100,000 women (Figure 6). ${ }^{189}$ It accounts 


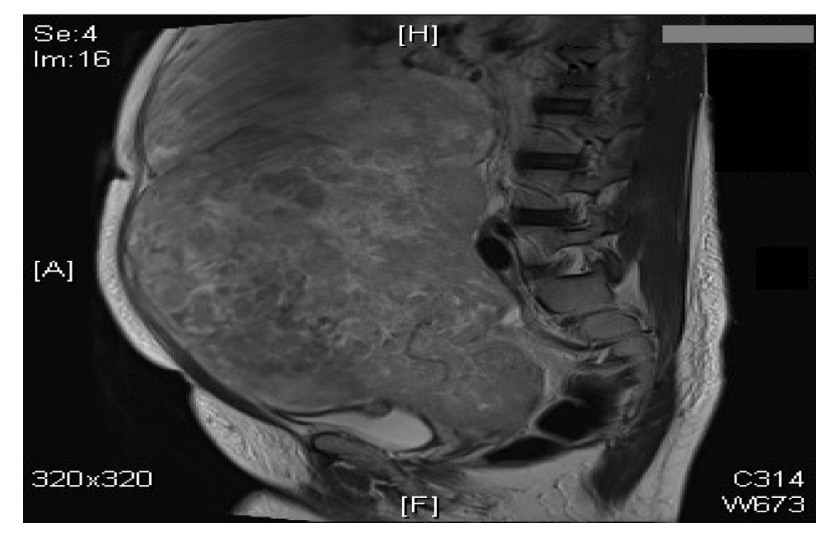

Figure 6 A 40-year-old woman with a large abdomino-pelvic mass, which turned out to be an aggressive leiomyosarcoma.

for $<5 \%$ of all uterine malignancies and approximately $30 \%$ of all uterine sarcomas. ${ }^{190}$ The disease is characterized by a propensity for early hematogenous spread, leading to high local and distant failure rates. ${ }^{191-193}$ In contrast to the much more common uterine adenocarcinoma, lymphatic spread is a rare event, and the overall prognosis is poor. ${ }^{194}$ They are considered neoplasms of high metastatic potential with 5-year overall survival rates varying between $0 \%$ and $73 \%$. ${ }^{195-197}$

Most occur in women over 40 years of age who usually present with abnormal vaginal bleeding (56\%), palpable pelvic mass (54\%), and pelvic pain (22\%). Signs and symptoms resemble those of the far more common leiomyoma and preoperative distinction between the two tumors may be difficult. ${ }^{198}$ Nevertheless, malignancy should be suspected by the presence of certain clinical behaviors, such as tumor growth in menopausal women who are not on hormonal replacement therapy. ${ }^{199}$ Occasionally, the presenting manifestations are related to tumor rupture (hemoperitoneum), extra-uterine extension (one-third to one-half of cases), or metastases. ${ }^{198}$ Most leiomyosarcomas arise de novo, but an apparent minority of leiomyosarcomas may represent leiomyomas that have undergone malignant transformation. ${ }^{200}$

Treatment of leiomyosarcomas includes total abdominal hysterectomy and debulking of tumor if present outside the uterus. Removal of the ovaries and lymph node dissection remain controversial as metastases to these organs occur in a small percentage of cases and are frequently associated with intraabdominal disease. ${ }^{201}$ Ovarian preservation may be considered in premenopausal patients with early-stage leiomyosarcomas. ${ }^{201}$ Lymph node metastases have been identified in $6.6 \%$ and $11 \%$ of two series of patients with leiomyosarcoma who underwent lymphadenectomy. ${ }^{201,202}$ In the first series, the 5-year diseasespecific survival rate was $26 \%$ in patients who had positive lymph nodes compared with $64.2 \%$ in patients who had negative lymph nodes $(P<0.001) .{ }^{202}$ The influence of adjuvant therapy on survival is uncertain. Radiotherapy may be useful in controlling local recurrences and chemotherapy with doxorubicin or docetaxel/gemcitabine is now used for advanced or recurrent disease, with response rates ranging from $27 \%$ to $36 \%{ }^{203,204}$ Some patients may respond to hormonal treatment. ${ }^{205}$

\section{Conclusion}

Although they are essentially benign, uterine fibroids are associated with significant morbidity to nearly $40 \%$ of women during their reproductive years and sometimes even after menopause. Therefore, there is considerable interest in discovering any etiological clues in factors including dietary, stress, and environmental influences. The most practical investigative modality has always been gray-scale ultrasonography, but with the developments of innovative methods of treatments, it is not just enough to diagnose the presence of the fibroid, but also its dynamic relation with surrounding tissue as well. With more and more patients demanding a nonsurgical approach to their symptoms, there is a developing market for selective estrogen and especially progesterone receptor modulators, and exploring the role of aromatase inhibitors, vitamin $\mathrm{D}$, and green tea extract.

Gone are the days when the only surgical approach for fibroids was offering a myomectomy or hysterectomy. The concept of vascular embolization has altered the playing field and allowed women to preserve their fertility status without resorting to surgery. This is being further investigated by the FEMME (A randomised trial of treating Fibroids with either Embolisation or Myomectomy to Measure the Effect on quality of life among women wishing to avoid hysterectomy) trial (to measure and compare the changes in the quality of life women experience when their fibroids are treated by either myomectomy or uterine artery embolization).

Minimally invasive management of fibroids has been even further enriched by the development and introduction of novel techniques (ie, MRgFUS, VizAblate ${ }^{\mathrm{TM}}$, and Acessa ${ }^{\mathrm{TM}}$ ).

\section{Disclosure}

A T Khan reports no conflicts of interest in this work. M Shehmar has conducted training workshops for Ethicon, while J K Gupta has conducted training workshops for Ethicon and is a principal investigator for the FEMME study.

\section{References}

1. Ryan GL, Syrop CH, Van Voorhis BJ. Role, epidemiology, and natural history of benign uterine mass lesions. Clin Obstet Gynecol. 2005;48: $312-324$. 
2. Wallach EE, Vlahos NF. Uterine myomas: an overview of development, clinical features, and management. Obstet Gynecol. 2004;104: 393-406.

3. Sankaran S, Manyonda IT. Medical management of fibroids. Best Pract Res Clin Obstet Gynaecol. 2008;22(4):655-676.

4. Parker WH. Etiology, symptomatology, and diagnosis of uterine myomas. Fertil Steril. 2007;87(4):725-736.

5. Rein MS, Barbieri RL, Friedman AJ. Progesterone: a critical role in the pathogenesis of uterine myomas. Am J Obstet Gynecol. 1995;172(1 Pt1): 14-18.

6. Andersen J. Growth factors and cytokines in uterine leiomyomas. Semin Reprod Endocrinol. 1996;14(3):269-282.

7. Fields KR, Neinstein LS. Uterine myomas in adolescents: case reports and a review of the literature. J Pediatr Adolesc Gynecol. 1996;9(4): 195-198.

8. Cramer SF, Patel A. The frequency of uterine leiomyomas. Am J Clin Pathol. 1990;94(4):435-438.

9. Day Baird D, Dunson DB, Hill MC, Cousins D, Schectman JM. High cumulative incidence of uterine leiomyoma in black and white women: ultrasound evidence. Am J Obstet Gynecol. 2003;188(1): $100-107$.

10. Laughlin SK, Schroeder JC, Baird DD. New directions in the epidemiology of uterine fibroids. Semin Reprod Med. 2010;28(3):204-217.

11. Schwartz SM. Epidemiology of uterine leiomyomata. Clin Obstet Gynecol. 2001;44(2):316-326.

12. Purdie DM, Green AC. Epidemiology of endometrial cancer. Best Pract Res Clin Obstet Gynaecol. 2001;15(3):341-354.

13. Colditz GA. Epidemiology of breast cancer. Findings from the nurses' health study. Cancer. 1993;71(Suppl 4):1480-1489.

14. Baird DD, Dunson DB. Why is parity protective for uterine fibroids? Epidemiology. 2003;14(2):247-250.

15. Parazzini F. Risk factors for clinically diagnosed uterine fibroids in women around menopause. Maturitas. 2006;55(2):174-179.

16. Wise LA, Palmer JR, Harlow BL, et al. Reproductive factors, hormonal contraception, and risk of uterine leiomyomata in African-American women:a prospective study. Am J Epidemiol. 2004;159(2):113-123.

17. Burbank F. Childbirth and myoma treatment by uterine artery occlusion: do they share a common biology? JAm Assoc Gynecol Laparosc. 2004;11(2):138-152.

18. Wise LA, Palmer JR, Harlow BL, et al. Risk of uterine leiomyomata in relation to tobacco, alcohol and caffeine consumption in the Black Women's Health Study. Hum Reprod. 2004;19(8):1746-1754.

19. Stewart EA, Nowak RA. New concepts in the treatment of uterine leiomyomas. Obstet Gynecol. 1998;92(4 Pt 1):624-627.

20. Leppert PC, Catherino WH, Segars JH. A new hypothesis about the origin of uterine fibroids based on gene expression profiling with microarrays. Am J Obstet Gynecol. 2006;195(2):415-420.

21. Cramer SF, Mann L, Calianese E, Daley J, Williamson K. Association of seedling myomas with myometrial hyperplasia. Hum Pathol. 2009;40(2):218-225.

22. Rogers R, Norian J, Malik M, et al. Mechanical homeostasis is altered in uterine leiomyoma. Am J Obstet Gynecol. 2008;198(4):474.

23. Catherino W, Salama A, Potlog-Nahari C, Leppert P, Tsibris J, Segars J. Gene expression studies in leiomyomata: new directions for research. Semin Reprod Med. 2004;22(2):83-90.

24. Baird DD, Kesner JS, Dunson DB. Luteinizing hormone in premenopausal women may stimulate uterine leiomyomata development. J Soc Gynecol Investig. 2006;13(2):130-135.

25. Wirth MM, Meier EA, Fredrickson BL, Schultheiss OC. Relationship between salivary cortisol and progesterone levels in humans. Biol Psychol. 2007;74(1):104-107.

26. National Institute for Health and Clinical Excellence. Uterine Artery Embolisation for Fibroids. London: NICE; 2010. Available from: http:// www.nice.org.uk/nicemedia/live/11025/51706/51706.pdf. Accessed on October 21, 2013.

27. Sabry M, Al-Hendy A. Innovative oral treatments of uterine leiomyoma. Obstet Gynecol Int. 2012;2012:943635. doi:10.1155/2012/943635
28. Schwartz SM, Marshall LM, Baird DD. Epidemiologic contributions to understanding the etiology of uterine leiomyomata. Environ Health Perspect. 2000;108(Supp1 5):821-827.

29. Okolo S. Incidence, aetiology and epidemiology of uterine fibroids. Best Pract Res Clin Obstet Gynaecol. 2008;22(4):571-588.

30. Wegienka G, Baird DD, Hertz-Picciotto I, et al. Self-reported heavy bleeding associated with uterine leiomyomata. Obstet Gynecol. 2003;101(3):431-437.

31. Lippman SA, Warner M, Samuels S, Olive D, Vercellini P, Eskenazi B. Uterine fibroids and gynecologic pain symptoms in a population-based study. Fertil Steril. 2003;80(6):1488-1494.

32. Zimmermann A, Bernuit D, Gerlinger C, Schaefers M, Geppert K. Prevalence, symptoms and management of uterine fibroids: an international internet-based survey of 21,746 women. BMC Womens Health. 2012;12:6.

33. Somigliana E, Vercellini P, Daguati R, Pasin R, De Giorgi O, Crosignani PG. Fibroids and female reproduction:a critical analysis of the evidence. Hum Reprod Update. 2007;13:465-476.

34. Parker, WH. Etiology, symptomatology, and diagnosis of uterine myomas. Fertil Steril. 2007;87(4):725-736.

35. Levens ED, Wesley R, Premkumar A, Blocker W, Nieman LK. Magnetic resonance imaging and transvaginal ultrasound for determining fibroid burden: implications for research and clinical care. Am JObstet Genecol. 2009;200(5):537. e1-e7.

36. Volkers NA, Hehenkamp WJ, Spijkerboer AM, et al. MR reproducibility in the assessment of uterine fibroids for patients scheduled for uterine artery embolization. Cardiovasc Intervent Radiol. 2008;31: 260-268.

37. Zawin M, McCarthy S, Scoutt LM, Comite F. High-field MRI and US evaluation of the pelvis in women with leiomyomas. Magn Reson Imaging. 1990;8:371-376.

38. Dueholm M, Lundorf E, Hansen ES, Ledertoug S, Olesen F. Evaluation of the uterine cavity with magnetic resonance imaging, transvaginal sonography, hysterosonographic examination, and diagnostic hysteroscopy. Fertil Steril. 2001;76:350-357.

39. Dueholm M, Lundorf E, Sorensen JS, Ledertoug S, Olesen F, Laursen H. Reproducibility of evaluation of the uterus by transvaginal sonography, hysterosonographic examination, hysteroscopy and magnetic resonance imaging. Hum Reprod. 2002;17:195-200.

40. Wilde S, Scott-Barrett S. Radiological appearances of uterine fibroids. Indian J Radiol Imaging. 2009;19(3):222-231.

41. Roy C, Bierry G, El Ghali S, Buy X, Rossini A. Acute torsion of uterine leiomyoma: CT features. Abdom Imaging. 2005;30:120-123.

42. Dueholm M, Lundorf E, Hansen ES, Ledertoug S, Olesen F. Accuracy of magnetic resonance imaging and transvaginal ultrasonography in the diagnosis, mapping, and measurement of uterine myomas. Am J Obstet Gynecol. 2002;186:409-415.

43. Weinreb JC, Barkoff ND, Megibow A, Demopoulos R. The value of MR imaging in distinguishing leiomyomas from other solid pelvic masses when sonography is indeterminate. AJR Am J Roentgenol. 1989;154: 295-299.

44. Omari, EA, Varghese T, Kliewer MA. A novel saline infusion sonohysterography-based strain imaging approach for evaluation of uterine abnormalities in vivo: preliminary results. J Ultrasound Med. 2012;31(4):609-615.

45. Davidson KG, Dubinsky TJ. Ultrasonographic evaluation of the endometrium in postmenopausal vaginal bleeding. Radiol Clin North Am. 2003;41:769-780.

46. Cohen JR, Luxman D, Sagi J, Yovel I, Wolman I, David MP. Sonohysterography for distinguishing endometrial thickening from endometrial polyps in postmenopausal bleeding. Ultrasound Obstet Gynecol. 1994;4:227-230.

47. Byun JY, Kim SE, Choi BG, et al. Diffuse and focal adenomyosis: MR imaging findings. RadioGraphics. 1999;19(Suppl 1):s161-s170.

48. Ascher SM, Arnold LL, Patt RH, et al. Adenomyosis: Prospective comparison of MR imaging and transvaginal sonography. Radiology. 1994;190:803-806. 
49. Dudiak CM, Turner DA, Patel SK, Archie JT, Silver B, Norusis M. Uterine leiomyomas in the infertile patient: preoperative localization with MR imaging versus US and hysterosalpingography. Radiology. 1988; 167:627-663.

50. Roche O, Chavan N, Aquilina J, Rockall A. Radiological appearances of gynaecological emergencies. Insights Imaging. 2012;3(3): 265-275.

51. Livermore JA, Adusumilli S. MRI of benign uterine conditions. Appl Radiol. 2007;36(9):8-18.

52. Brosens JJ, de Souza NM, Barker FG. Uterine junctional zone: function and disease. Lancet. 1995;346:558-560.

53. Murase E, Siegelman ES, Outwater EK, et al. Uterine leiomyomas: histopathologic features, MR imaging findings, differential diagnosis, and treatment. Radiographics. 1999;19:1179-1197.

54. Ueda H, Togashi K, Konishi I, et al. Unusual appearances of uterine leiomyomas: MR imaging findings and their histopathologic backgrounds. Radiographics. 1999;19(Suppl 1):s131-s145.

55. Kim JC, Kim SS, Park JY. "Bridging vascular sign” in the MR diagnosis of exophytic uterine leiomyoma. J Comput Assist Tomogr. 2000;24: 57-60.

56. Dohke M, Watanabe Y, Okumura A, et al. Comprehensive MR Imaging of acute gynecologic diseases. Radiographics. 2000;20(6):1551-1566.

57. Burn PR, McCall JM, Chinn RJ, Vashisht A, Smith JR, Healy JC. Uterine fibroleiomyoma: MR imaging appearance before and after embolization of uterine arteries. Radiology. 2000;214:729-734.

58. Simms-Stewart D, Fletcher H. Counselling patients with uterine fibroids: a review of the management and complications. Obstet Gynecol Int 2012;2012:539365. doi: 10.1155/2012/539365

59. Pritts EA, Olive DL. When should uterine fibroids be treated? Curr Obstet Gynecol Rep. 2012;1(2):71-80.

60. Carlson KJ, Miller BA, Fowler FJ. The Maine Women's Health Study: I. Outcomes of hysterectomy. Obstet Gynecol. 1994;83:556.

61. Lefebvre G, Vilos G, Allaire C, et al. The management of uterine leiomyomas. J Obstet Gynaecol Can. 2003;25:396.

62. Laughlin SK, Stewart EA. Uterine leiomyomas: individualizing the approach to a heterogeneous condition. Obstet Gynecol. 2011; 117(2 Pt 1):396-403.

63. Lakhani KP, Marsh MS, Purcell W, Hardiman P. Uterine artery blood flow parameters in women with dysfunctional uterine bleeding and uterine fibroids: the effects of tranexamic acid. Ultrasound Obstet Gynecol. 1998;11:283-285.

64. Sundström A, Seaman H, Kieler H, Alfredsson L. The risk of venous thromboembolism associated with the use of tranexamic acid and other drugs used to treat menorrhagia: a case-control study using the General Practice Research Database. BJOG. 2009;116:91-97.

65. Ip PP, Lam KW, Cheung CL, et al. Tranexamic acid-associated necrosis and intralesional thrombosis of uterine leiomyomas: a clinicopathologic study of 147 cases emphasizing the importance of drug-induced necrosis and early infarcts in leiomyomas. Am J Surg Pathol. 2007;31: 1215-1224.

66. Abdel-Rahman MY, Sabry M, Al-Hendy A. Medical Treatment of Fibroid to Decrease Rate of Hysterectomy. In: Al-Hendy A, editor. Hysterectomy. Rejeka: InTech; 2012:115-128.

67. Marshall LM, Spiegelman D, Goldman MB, et al. A prospective study of reproductive factors and oral contraceptive use in relation to the risk of uterine leiomyomata. Fertil Steril. 1998;70(3):432-439.

68. Chiaffarino F, Parazzini F, La Vecchia C, Marsico S, Surace M, Ricci E. Use of oral contraceptives and uterine fibroids: results from a casecontrol study. Br J Obstet Gynaecol. 1999;106(8):857-860.

69. Parazzini F, Negri E, La Vecchia C, Fedele L, Rabaiotti M, Luchini L. Oral contraceptive use and risk of uterine fibroids. Obstet Gynecol. 1992;79(3):430-433.

70. Friedman AJ, Daly M, Juneau-Norcross M, Gleason R, Rein MS, LeBoff M. Long-term medical therapy for leiomyomata uteri: a prospective, randomized study of leuprolide acetate depot plus either estrogen-progestin or progestin 'add-back' for 2 years. Hum Reprod. 1994;9(9):1618-1625.
71. Orsini G, Laricchia L, Fanelli M. [Low-dose combination oral contraceptives use in women with uterine leiomyomas]. Minerva Ginecol. 2002;54(3):253-261. Italian.

72. Venkatachalam S, Bagratee JS, Moodley J. Medical management of uterine fibroids with medroxyprogesterone acetate (Depo Provera): a pilot study. J Obstet Gynaecol. 2004;24(7):798-800.

73. The management of menorrhagia in secondary care. Evidence-based clinical guideline No 5. London: Royal College of Obstetricians and Gynaecologists; 1999.

74. Irvine GA, Campbell-Brown MB, Lumsden MA, et al. Randomised comparative trial of the levonorgestrel intrauterine system and norethisterone for treatment of idiopathic menorrhagia. $\mathrm{Br} \mathrm{J} \mathrm{Obstet}$ Gynaecol. 1998;105:592-598.

75. Maruo T, Laoag-Fernandez JB, Pakarinen P, et al. Effects of the levonorgestrel-releasing intrauterine system on proliferation and apoptosis in the endometrium. Hum Reprod. 2001;16:2103-2108.

76. Maruo T, Ohara N, Matsuo H, et al. Effects of levonorgestrel-releasing IUS and progesterone receptor modulator PRM CDB-2914 on uterine leiomyomas. Contraception. 2007;75:S99-S103.

77. National Collaborating Centre for Women's and Children's Health. Heavy menstrual bleeding: clinical guideline. London: National Institute for Clinical Excellence; 2007.

78. Bozzini N, Rodrigues CJ, Petti DA, et al. Effects of treatment with gonadotropin releasing hormone agonist on the uterine leiomyomata structure. Acta Obstet Gynecol Scand. 2003;82:330-334.

79. Chegini N, Kornberg L. Gonadotropin releasing hormone analogue therapy alters signal transduction pathways involving mitogen-activated protein and focal adhesion kinases in leiomyoma. J Soc Gynecol Investig. 2003;10:21-26.

80. Chegini N, Ma C, Tang XM, et al. Effects of GnRH analogues, 'addback' steroid therapy, antiestrogen and antiprogestins on leiomyoma and myometrial smooth muscle cell growth and transforming growth factor-beta expression. Mol Hum Reprod. 2002;12:1071-1078.

81. Chegini N, Verala J, Luo X, et al. Gene expression profile of leiomyoma and myometrium and the effect of gonadotropin releasing hormone analogue therapy. J Soc Gynecol Investig. 2003;10:161-171.

82. Deligdisch L, Hirschmann S, Altchek S. Pathologic changes in gonadotropin releasing hormone agonist analogue treated uterine leiomyomata. Fertil Steril. 1997;67:837-841.

83. Reinsch RC, Murphy AA, Morales AJ, et al. The effects of RU 486 and leuprolide acetate on uterine artery blood flow in the fibroid uterus: a prospective, randomized study. Am J Obstet Gynecol. 1994;170: 1623-1628.

84. Mesia AF, Gahr D, Wild M, et al. Immunohistochemistry of vascular changes in leuprolide acetate treated leiomyomas. Am J Obstet Gynecol. 1997;176:1026-1029.

85. Rutgers JL, Spong CY, Sinow R, et al. Leuprolide acetate treatment and myoma arterial size. Obstet Gynecol. 1995;86:386-388.

86. Lethaby A, Vollenhoven B, Sowter M. Pre-operative GnRH analogue therapy before hysterectomy or myomectomy for uterine fibroids. Cochrane Database Syst Rev. 2000;2:CD000547.

87. Mitlak BH, Cohen FJ. In search of optimal long-term female hormone replacement: the potential of selective estrogen receptor modulators. Horm Res. 1997;48(4):155-163.

88. Palomba S, Sammartino A, Di Carlo C, Affinito P, Zullo F, Nappi C. Effects of raloxifene treatment on uterine leiomyomas in postmenopausal women. Fertil Steril. 2001;76(1):38-43.

89. Palomba S, Orio F Jr, Russo T, et al. Antiproliferative and proapoptotic effects of raloxifene on uterine leiomyomas in postmenopausal women. Fertil Steril. 2005;84(1):154-161.

90. Premkumar A, Venzon DJ, Avila N, et al. Gynecologic and hormonal effects of raloxifene in premenopausal women. Fertil Steril. 2007;88(6):1637-1644.

91. Giangrande PH, McDonnell DP. The A and B isoforms of the human progesterone receptor: two functionally different transcription factors encoded by a single gene. Recent Prog Horm Res. 1999;54: 291-313. 
92. Spitz IM. Clinical utility of progesterone receptor modulators and their effect on the endometrium. Curr Opin Obstet Gynecol. 2009;21: 318-324.

93. Maruo T, Matsuo H, Samoto T, et al. Effects of progesterone on uterine leiomyoma growth and apoptosis. Steroids. 2000;65:585-592.

94. Talaulikar VS, Manyonda I. Progesterone and progesterone receptor modulators in the management of symptomatic uterine fibroids. Eur J Obstet Gynecol Reprod Biol. 2012;165:135-140.

95. De Leo V, Morgante G, La Marca A, et al. A benefit-risk assessment of medical treatment for uterine leiomyomas. Drug Safety. 2002;25: 759-779.

96. Eisinger SH, Meldrum S, Fiscella K, le Roux HD, Guzick DS Low-dose mifepristone for uterine leiomyomata. Obstetr Gynecol. 2003;101:243-250.

97. Carbonell Esteve JL, Acosta R, Heredia B, Pérez Y, Castañeda MC, Hernández AV. Mifepristone for the treatment of uterine leiomyomas: a randomized controlled trial. Obstet Gynecol. 2008;112: 1029-1036.

98. Donnez J, Tatarchuk TF, Bouchard P, et al; PEARL I Study Group. Ulipristal acetate versus placebo for fibroid treatment before surgery. N Engl J Med. 2012;366:409-420.

99. Donnez J, Tomaszewski J, Vázquez F, et al; PEARL II Study Group. Ulipristal acetate versus leuprolide acetate for uterine fibroids. $N$ Engl J Med. 2012;366:421-432.

100. Fiscella K, Eisinger S. CDB-2914 for uterine leiomyomata treatment: a randomized controlled trial. Obstet Gynecol. 2008;112(3):707; author reply 707-708.

101. Smith IE, Dowsett M. Aromatase inhibitors in breast cancer. $N$ Engl J Med. 2003;348(24):2431-2442.

102. Ishikawa $\mathrm{H}$, Reierstad $\mathrm{S}$, Demura $\mathrm{M}$, et al. High aromatase expression in uterine leiomyoma tissues of African-American women. J Clin Endocrinol Metab. 2009;94(5):1752-1756.

103. Williams AR, Critchley HO, Osei J, et al. The effects of the selective progesterone receptor modulator asoprisnil on the morphology of uterine tissues after 3 months treatment in patients with symptomatic uterine leiomyomata. Hum Reprod. 2007;22(6):1696-1704.

104. Bedaiwy MA, Lui J. Long-term management of endometriosis: medical therapy and treatment of infertility. Sex Reprod Menopause. 2010;8(3):5.

105. Baird DT, Brown A, Cheng L, et al. Mifepristone: a novel estrogen-free daily contraceptive pill. Steroids. 2003;68(10-13):1099-1105.

106. Varelas FK, Papanicolaou AN, Vavatsi-Christaki N, Makedos GA, Vlassis GD. The effect of anastrazole on symptomatic uterine leiomyomata. Obstet Gynecol. 2007;110(3):643-649.

107. American University of Beirut Medical Center. Aromatase inhibitors for treatment of uterine leiomyomas. Available from: http://clinicaltrials. gov/show/NCT00945360. NLM identifier: NCT00945360. Accessed September 7, 2010.

108. Höppener JW, Mosselman S, Roholl PJ, et al. Expression of insulinlike growth factor-I and -II genes in human smooth muscle tumors. EMBO J. 1988;7(5):1379-1385.

109. Gloudemans T, Prinsen I, Van Unnik JA, Lips CJ, Den Otter W, Sussenbach JS. Insulin-like growth factor gene expression in human smooth muscle tumors. Cancer Res. 1990;50(20):6689-6695.

110. Norstedt G, Levinovitz A, Eriksson H. Regulation of uterine insulinlike growth factor I mRNA and insulin-like growth factor II mRNA by estrogen in the rat. Acta Endocrinol (Copenh). 1989;120(4): 466-472.

111. Rein MS, Friedman AJ, Pandian MR, Heffner LJ. The secretion of insulin-like growth factors I and II by explant cultures of fibroids and myometrium from women treated with a gonadotropin-releasing hormone agonist. Obstet Gynecol. 1990;76(3 Pt 1):388-394.

112. Boehm KD, Daimon M, Gorodeski IG, Sheean LA, Utian WH, Ilan J. Expression of the insulin-like and platelet-derived growth factor genes in human uterine tissues. Mol Reprod Dev. 1990;27(2):93-101.

113. Cohen O, Schindel B, Homburg R. Uterine leiomyomata - a feature of acromegaly. Hum Reprod. 1998;13(7):1945-1946.
114. Nilsson CG, Luukkainen T, Diaz J, Allonen H. Intrauterine contraception with levonorgestrel: a comparative randomised clinical performance study. Lancet. 1981;1(8220 Pt 1):577-580.

115. De Leo V, la Marca A, Morgante G, Severi FM, Petraglia F. Administration of somatostatin analogue reduces uterine and myoma volume in women with uterine leiomyomata. Fertil Steril. 2001;75(3):632-633.

116. Feelders RA, Hofland LJ, van Aken MO, et al. Medical therapy of acromegaly: efficacy and safety of somatostatin analogues. Drugs. 2009;69(16):2207-2226.

117. Davies PH, Stewart SE, Lancranjan L, Sheppard MC, Stewart PM. Long-term therapy with long-acting octreotide (Sandostatin-LAR ${ }^{\circledR}$ ) for the management of acromegaly. Clin Endocrinol (Oxf). 1998;48(3): 311-316.

118. Melli MS, Farzadi L, Madarek EO. Comparison of the effect of gonadotropin releasing hormone analog (Diphereline) and Cabergoline (Dostinex) treatment on uterine myoma regression. Saudi Med J. 2007;28(3):445-450.

119. Sayyah-Melli M, Tehrani-Gadim S, Dastranj-Tabrizi A, et al. Comparison of the effect of gonadotropin-releasing hormone agonist and dopamine receptor agonist on uterine myoma growth. Histologic, sonographic, and intra-operative changes. Saudi Med J. 2009;30(8): 1024-1033.

120. La Marca A, Giulini S, Vito G, Orvieto R, Volpe A, Jasonni VM. Gestrinone in the treatment of uterine leiomyomata: effects on uterine blood supply. Fertil Steril. 2004;82(6):1694-1696.

121. Coutinho EM. Treatment of large fibroids with high doses of gestrinone. Gynecol Obstet Invest. 1990;30(1):44-47.

122. Sharan C, Halder SK, Thota C, Jaleel T, Nair S, Al-Hendy A. Vitamin D inhibits proliferation of human uterine leiomyoma cells via catecholO-methyltransferase. Fertil Steril. 2011;95(1):247-253.

123. Halder SK, Goodwin JS, Al-Hendy A. 1,25-Dihydroxyvitamin D3 reduces TGF-beta3-induced fibrosis-related gene expression in human uterine leiomyoma cells. J Clin Endocrinol Metab. 2011;96(4): E754-E762.

124. Halder SK, Goodwin S, Al-Hendy A. Vitamin D exhibits antiestrogenic effects in human uterine leiomyoma cells. Fertil Steril. 2010;94(4):S219-S220.

125. Halder SK, Sharan C, Goodwin S,Al-Hendy A. 1,25 dihydroxyvitamin D3 disorganizes actin fibers in human immortalized uterine leiomyoma cells. Fertil Steril. 2009;92(3):S127-S128.

126. Khan N, Mukhtar H. Tea polyphenols for health promotion. Life Sci. 2007;81(7):519-533.

127. Chung JE, Kurisawa M, Kim YJ, Uyama H, Kobayashi S. Amplification of antioxidant activity of catechin by polycondensation with acetaldehyde. Biomacromolecules. 2004;5(1):113-118.

128. Khan N, Afaq F, Saleem M, Ahmad N, Mukhtar H. Targeting multiple signaling pathways by green tea polyphenol (-)-epigallocatechin-3gallate. Cancer Res. 2006;66(5):2500-2505.

129. Zhang D, Al-Hendy M, Richard-Davis G, Montgomery-Rice V, Rajaratnam V, Al-Hendy A. Antiproliferative and proapoptotic effects of epigallocatechin gallate on human leiomyoma cells. Fertil Steril. 2010;94(5):1887-1893.

130. van der Kooij SM, Ankum WM, Hehenkamp WJ. Review of nonsurgical/minimally invasive treatments for uterine fibroids. Curr Opin Obstet Gynecol. 2012;24(6):368-375.

131. Spies JB, Sacks D. Credentials for uterine artery embolization. J Vasc Interv Radiol. 2004;15:111-113.

132. Greenwood C, Glickman M, Schwartz P, Morse SS, Denny DF. Obstetric and non-malignant gynecologic bleeding: treatment with angiographic embolization radiology. Radiology. 1987;164(1): $155-159$.

133. Goodwin S, Vendantham S, McLucas B, Forno A, Perella R. Preliminary experience with uterine fibroid embolization for uterine fibroids. J Vasc Interv Radiol. 1997;8:517-526.

134. Ravina JH, Bouret JM, Ciraru-Vigneron N, et al. [Recourse to particular arterial embolization in the treatment of some uterine leiomyoma]. Bull Acad Natl Med. 1997;181(2):233-243. French. 
135. Ravina JH, Herbreteau D, Ciraru-Vigneron N, et al. Arterial embolisation to treat uterine myomata. Lancet. 1995;346:671-672.

136. Hutchins FL Jr, Worthington-Kirsch R, Berkowitz RP. Selective uterine artery embolization as primary treatment for symptomatic leiomyomata uteri. J Am Assoc Gynecol Laparosc. 1999;6:279-284.

137. Spies JB, Scialli AR, Jha RC, et al. Initial results from uterine fibroid embolization for symptomatic leiomyomata. J Vasc Interv Radiol. 1999;10:1149-1157.

138. Pelage JP, Le Dref O, Soyer P, et al. Fibroid-related menorrhagia: treatment with superselective embolization of the uterine arteries and midterm follow-up. Radiology. 2000;215:428-431.

139. Walker WJ, Pelage JP. Uterine artery embolisation for symptomatic fibroids: clinical results in 400 women with imaging follow-up. $\mathrm{Br} J$ Obstet Gynecol. 2002;109:1263-1272.

140. Pron G, Bennett J, Common A, Wall J, Asch M, Sniderman K. The Ontario Uterine Fibroid Embolization Trial. Part 2. Uterine fibroid reduction and symptom relief after uterine artery embolization for fibroids. Fertil Steril. 2003;79:120-127.

141. Spies JB, Allison S, Flick P, et al. Polyvinyl alcohol particles and tris-acryl gelatin microspheres for uterine artery embolization for leiomyomas: results of a randomized comparative study. JVasc Interv Radiol. 2004;15:793-800.

142. Aitken E, Khaund A, Hamid SA, Millan D, Campbell S. The normal human myometrium has a vascular spatial gradient absent in smal fibroids. Hum Reprod. 2006;21:2669-2678.

143. Banu NS, Gaze DC, Bruce H, Collinson PO, Belli AM, Manyonda IT. Markers of muscle ischemia, necrosis, and inflammation following uterine artery embolization in the treatment of symptomatic uterine fibroids. Am J Obstet Gynecol. 2007;196:213. e1-e5.

144. Andrews RT, Brown PH. Uterine artery embolization: factors influencing patient radiation exposure. Radiology. 2000;217: 713-722.

145. Nikolic B, Abbara S, Levy E, et al. Influence of radiographic technique and equipment on adsorbed ovarian dose associated with uterine artery embolization. J Vasc Interv Radiol. 2000;11:1173-1178.

146. Zupi E, Pocek M, Dauri M, et al. Selective uterine artery embolization in the management of uterine myomas. Fertil Steril. 2003;79: 107-111.

147. White AM, Banovac F, Spies JB. Patient radiation exposure during uterine fibroid embolization and the dose attributable to aortography J Vasc Interv Radiol. 2007;18:573-576.

148. Worthington-Kirsch R, Koller NE. Time course of pain after uterine artery embolization for fibroid disease. Medscape Womens Health 2002;7(2):4.

119. Spies JB, Ascher SA, Roth AR, Kim J, Levy EB, Gomez-Jorge J. Uterine artery embolization for leiomyomata. Obstet Gynecol. 2001;98:29-34.

150. Pron G, Mocarski E, Bennet J, et al. Tolerance, hospital stay, and recovery after uterine artery embolization for fibroids: the Ontario Uterine Fibroid Embolization Trial. J Vasc Interv Radiol. 2003;14: 1243-1250.

151. Bruno J, Sterbis K, Flick P, et al Recovery after uterine artery embolization for leiomyomas: a detailed analysis of its duration and severity. J Vasc Interv Radiol. 2004;15:801-807.

152. Worthington-Kirsch R, Spies JB, Myers ER, et al. The Fibroid Registry for Outcomes Data (FIBROID) for uterine embolization: short term outcomes. Obstet Gynecol. 2005;106:52-59.

153. Tropeano G, Amoroso S, Scambia G. Non-surgical management of uterine fibroids. Hum Reprod Update. 2008;14(3):259-274.

154. Lumsden MA. Modern management of fibroids. Obstet Gynaecol Reprod Med. 2010;20(3):82-86.

155. Gupta JK, Sinha A, Lumsden M, Hickey M. Uterine artery embolization for symptomatic uterine fibroids. Cochrane Database Syst Rev. 2012;5:CD005073.

156. Mara M, Fucikovaa Z, Maskova J, Kuzela J, Haakova L. Uterine fibroid embolization versus myomectomy in women wishing to preserve fertility: preliminary results of a randomized controlled trial. Eur $J$ Obstet Gynecol Reprod Biol. 2006;126:226-233.
157. Mara M, Maskova J, Fucikova Z, Kuzel D, Belsan T, Sosna O. Midterm clinical and first reproductive results of a randomized controlled trial comparing uterine fibroid embolization and myomectomy. Cardiovasc InterventRadiol. 2008;31:73-85.

158. Moss JG, Cooper KG, Khaund A, et al. Randomised comparison of uterine artery embolization (UAE) with surgical treatment in patients with symptomatic uterine fibroids (REST trial): 5 -year results. $B J O G$. 2011;118:936-944.

159. van der Kooij SM, Hehenkamp WJ, Volkers NA, et al. Uterine artery embolization vs hysterectomy in the treatment of symptomatic uterine fibroids: 5-year outcome from the randomized EMMY trial. Am J Obstet Gynecol. 2010;203:105. e1-e13.

160. Homer H, Saridogan E. Uterine artery embolization for fibroids is associated with an increased risk of miscarriage. Fertil Steril. 2010;94: 324-330.

161. Stewart EA, Gedroyc WM, Tempany CM, et al. Focused ultrasound treatment of uterine fibroid tumors:safety and feasibility of a noninvasive thermoablative technique. Am J Obstet Gynecol. 2003;189: $48-54$.

162. Tempany CM, Stewart EA, McDannold N, Quade BJ, Jolesz FA, Hynynen K. MR imaging-guided focused ultrasound surgery of uterine leiomyomas: a feasibility study. Radiology. 2003;226: 897-905.

163. Hindley J, Gedroyc WM, Regan L, et al. MRI guidance of focused ultrasound therapy of uterine fibroids: early results. AJR Am J Roentgenol. 2004;183:1713-1719.

164. Stewart EA, Rabinovici J, Tempany CM, et al. Clinical outcomes of focused ultrasound surgery for the treatment of uterine fibroids. Fertil Steril. 2006;85:22-29.

165. Voogt MJ, Trillaud H, Kim YS, et al. Volumetric feedback ablation of uterine fibroids using magnetic resonance-guided high intensity focused ultrasound therapy. Eur Radiol. 2012;22:411-417.

166. Rabinovici J, David M, Fukunishi H, et al. Pregnancy outcome after magnetic resonance-guided focused ultrasound surgery (MRgFUS) for conservative treatment of uterine fibroids. Fertil Steril. 2010;93: 199-209.

167. Maconochie N, Doyle P, Prior S, Simmons R. Risk factors for first trimester miscarriage; results from a UK-population-based casecontrol study. BJOG. 2007;114:170-186.

168. Garza-Leal JG, Toub D, Hernández León I, et al. Transcervical, intrauterine ultrasound-guided radiofrequency ablation of uterine fibroids with the VizAblate System: safety, tolerability, and ablation results in a closed abdomen setting. Gynecol Surg. 2011;8(3):327-334.

169. Lee BB. Radiofrequency ablation of uterine leiomyomata: a new minimally invasive hysterectomy alternative. Obstet Gynecol. 2002; 99(4):9S.

170. Chudnoff SG, Berman JM, Levine DJ, Harris M, Guido RS, Banks E. Outpatient procedure for the treatment and relief of symptomatic uterine myomas. Obstet Gynecol. 2013;121(5):1075-1082.

171. Schirmer BD. Intra-operative and laparoscopic ultrasound. In: Holzheimer RG, Mannick JA, editors. Surgical Treatment: Evidence-based and Problem-oriented. Munich: Zuckschwerdt; 2001.

172. Lethaby A, Vollenhoven B, Sowter MC. Pre-operative GnRH analogue therapy before hysterectomy or myomectomy for uterine fibroids. Cochrane Database Syst Rev. 2001;(2):CD000547.

173. Vessey MP, Villard-Mackintosh L, McPherson K, Coulter A, Yeates D. The epidemiology of hysterectomy: findings in a large cohort study. Br J Obstet Gynaecol. 1992;99:402-440.

174. Malek-Mellouli M, Ben Amara F, Youssef A, et al. Hysteroscopic myomectomy. Tunis Med. 2012;90:458-462.

175. Mavrelos D, Ben-Nagi J, Davies A, et al. The value of preoperative treatment with $\mathrm{GnRH}$ analogues in women with submucous fibroids: a double-blind, placebo-controlled randomized trial. Hum Reprod. 2010;25:2264-2269

176. Gambadauro P, Gudmundsson J, Torrejón R. Intrauterine adhesions following conservative treatment of uterine fibroids. Obstet Gynecol Int. 2012;2012:853269. 
177. Pritts EA, Parker WH, Olive DL. Fibroids and infertility: an updated systematic review of the evidence. Fertil Steril. 2009;91: 1215-1223.

178. Tinelli A, Hurst BS, Hudelist G, et al. Laparoscopic myomectomy focusing on the myoma pseudocapsule: technical and outcome reports. Hum Reprod. 2012;27:427-435.

179. Desai P, Patel P. Fibroids, infertility and laparoscopic myomectomy. J Gynecol Endosc Surg. 2011;2:36-42.

180. Kongnyuy EJ, Wiysonge CS. Interventions to reduce haemorrhage during myomectomy for fibroids. Cochrane Database Syst Rev. 2011:CD005355

181. Sawin SW, Pilevsky ND, Berlin JA, et al. Comparability of perioperative morbidity between abdominal myomectomy and hysterectomy for women with uterine leiomyomas. Am J Obstet Gynecol. 2000;183(6):1448-1455.

182. Machupalli S, Norkus EP, Mukherjee TK, Reilly KD. Abdominal Myomectomy Increases Fertility Outcome. Gynecol Obstet. 2013;3:144.

183. Salama SS, Kılıç GS. Uterine fibroids and current clinical challenges. J Turkish-German Gynecol Assoc. 2013;14:40-45.

184. Taran FA, Brown HL, Stewart EA. Racial diversity in uterine leiomyoma clinical studies. Fertil Steril. 2010;94:1500-1503.

185. hysterectomy-association.org.uk [homepage on the Internet]. Latest hysterectomy statistics in UK for the year 2011 to 2012. 2013 [updated January 2, 2013; cited June 24, 2013]. Available from: http:// www.hysterectomy-association.org.uk/index.php/research/latesthysterectomy-statistics-in-uk-for-the-year-2011-to-2012/. Accessed June 24, 2013.

186. Okolo S. Incidence, aetiology and epidemiology of uterine fibroids. Best Pract Res Clin Obstet Gynaecol. 2008;22:571-588.

187. NICE Clinical Guideline. Heavy Menstrual Bleeding. National Collaborating Centre for Women's and Children's Health. London: RCOG Press; 2007.

188. Royal College of Obstetricians and Gynaecologists. Consent Advice 4: Abdominal Hysterectomy for Benign Conditions. London: RCOG Press; 2009.

189. Harlow BL, Weiss NS, Lofton S. The epidemiology of sarcomas of the uterus. J Natl Cancer Inst. 1986;76:399-402.

190. Echt G, Jepson J, Steel J, et al. Treatment of uterine sarcomas. Cancer. 1990;66:35-39.

191. Rose PG, Piver MS, Tsukada Y, Lau T. Patterns of metastasis in uterine sarcoma. An autopsy study. Cancer. 1989;63:935-938.

192. Ueda SM, Kapp DS, Cheung MK, et al. Trends in demographic and clinical characteristics in women diagnosed with corpus cancer and their potential impact on the increasing number of deaths. Am J Obstet Gynecol. 2008;198:218. e1-e6.
193. Zivanovic O, Leitao MM, Iasonos A, et al. Stage-specific outcomes of patients with uterine leiomyosarcoma:a comparison of the International Federation of Gynecology and Obstetrics and American Joint Committee on Cancer staging systems. J Clin Oncol. 2009;27: 2066-2072.

194. Leitao MM, Sonoda Y, Brennan MF, Barakat RR, Chi DS. Incidence of lymph node and ovarian metastases in leiomyosarcoma of the uterus. Gynecol Oncol. 2003;91:209-212.

195. Yannopoulos K, Stout AP. Smooth muscle tumors in children. Cancer. 1962;15:958.

196. Weiss SW, Goldblum JR. Leiomyosarcoma. Enzinger and Weiss's Soft Tissue Tumors. 4th ed. Philadelphia: Mosby-Harcourt; 2001:p727-p748.

197. de Saint Aubain Somerhausen N, Fletcher CD. Leiomyosarcoma of soft tissue in children: clinicopathologic analysis of 20 cases. Am J Surg Pathol. 23(7):755-763.

198. D’Angelo E, Prat J. Uterine sarcomas :a review. Gynecol Oncol. 2010;116(1):131-139.

199. Perri T, Korach J, Sadetzki S, Oberman B, Fridman E, Ben-Baruch G. Uterine leiomyosarcoma: does the primary surgical procedure matter. Int J Gynecol Cancer. 2009;19:257-260.

200. van Meurs HS, Dieles JJ, Stel HV. A uterine leiomyoma in which a leiomyosarcoma with osteoclast-like giant cells and a metastasis of a ductal breast carcinoma are present. Ann Diagn Pathol. 2012;16(1): 67-70.

201. Giuntoli II RL, Metzinger DS, DiMarco CS, et al. Retrospective review of 208 patients with leiomyosarcoma of the uterus: prognostic indicators, surgical management, and adjuvant therapy. Gynecol Oncol. 2003;89:460-469.

202. Kapp DS, Shin JY, Chan JK. Prognostic factors and survival in 1396 patients with uterine leiomyosarcomas: emphasis on impact of lymphadenectomy and oophorectomy. Cancer. 2008;112:820-830.

203. Hensley ML, Blessing JA, Mannel R, Rose PG. Fixed-dose rate gemcitabine plus docetaxel as first-line therapy for metastatic uterine leiomyosarcoma: a Gynecologic Oncology Group phase II trial. Gynecol Oncol. 2008;109:329-334.

204. Hensley ML, Ishill N, Soslow R, et al. Adjuvant gemcitabine plus docetaxel for completely resected stages I-IV high grade uterine leiomyosarcoma: results of a prospective study. Gynecol Oncol. 2009;112:563-567.

205. Hardman MP, Roman JJ, Burnett AF, Santin AD. Metastatic uterine leiomyosarcoma regression using an aromatase inhibitor. Obstet Gynecol. 2007;110:518-520.
International Journal of Women's Health

\section{Publish your work in this journal}

The International Journal of Women's Health is an international, peerreviewed open-access journal publishing original research, reports, editorials, reviews and commentaries on all aspects of women's healthcare including gynecology, obstetrics, and breast cancer. The manuscript management system is completely online and includes

\section{Dovepress}

a very quick and fair peer-review system, which is all easy to use. Visit http://www.dovepress.com/testimonials.php to read real quotes from published authors. 